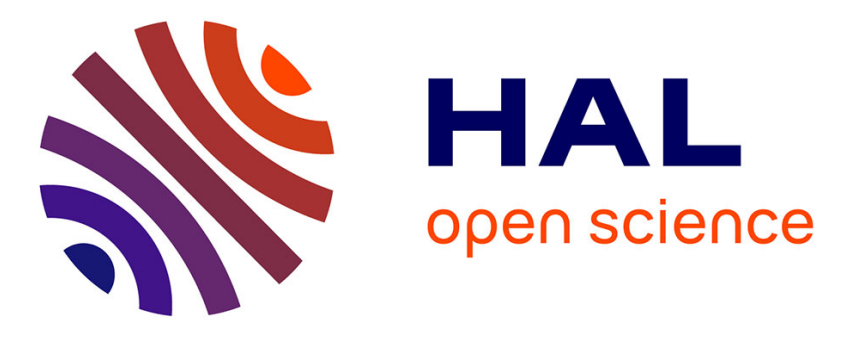

\title{
Managing biological invasions: the cost of inaction
}

Danish Ali Ahmed, Emma Judith Hudgins, Ross Noel Cuthbert, Melina

Kourantidou, Christophe Diagne, Phillip Joschka Haubrock, Brian Leung, Chunlong Liu, Boris Leroy, Sergei Petrovskii, et al.

\section{- To cite this version:}

Danish Ali Ahmed, Emma Judith Hudgins, Ross Noel Cuthbert, Melina Kourantidou, Christophe Diagne, et al.. Managing biological invasions: the cost of inaction. 2021. hal-03427568

\section{HAL Id: hal-03427568 https://hal.science/hal-03427568}

Preprint submitted on 18 Nov 2021

HAL is a multi-disciplinary open access archive for the deposit and dissemination of scientific research documents, whether they are published or not. The documents may come from teaching and research institutions in France or abroad, or from public or private research centers.
L'archive ouverte pluridisciplinaire HAL, est destinée au dépôt et à la diffusion de documents scientifiques de niveau recherche, publiés ou non, émanant des établissements d'enseignement et de recherche français ou étrangers, des laboratoires publics ou privés. 


\section{Managing biological invasions: the cost of inaction}

\section{Danish Ali Ahmed}

Gulf University for Science and Technology

Emma Judith Hudgins ( $\nabla$ emma.hudgins@mail.mcgill.ca )

Carleton University https://orcid.org/0000-0002-8402-5111

\section{Ross Noel Cuthbert}

Helmholtz Centre for Ocean Research: Helmholtz-Zentrum fur Ozeanforschung Kiel

\section{Melina Kourantidou}

Woods Hole Oceanographic Institution

\section{Christophe Diagne}

Université Paris-Saclay: Universite Paris-Saclay

\section{Phillip Joschka Haubrock}

Senckenberg Research Institute and Natural History Museum: Senckenberg Forschungsinstitut und Naturmuseum

\section{Brian Leung}

McGill University

\section{Chunlong Liu}

Université Paris-Saclay: Universite Paris-Saclay

\section{Boris Leroy}

Sorbonne University: Sorbonne Universite

\section{Sergei Petrovskii}

University of Leicester

Franck Courchamp

Université Paris-Saclay: Universite Paris-Saclay

\section{Research Article}

Keywords: InvaCost, invasive alien species, logistic growth, socio-economic impacts, prevention and biosecurity, long-term management

Posted Date: April 1st, 2021

DOI: https://doi.org/10.21203/rs.3.rs-300416/v1

License: (c) (i) This work is licensed under a Creative Commons Attribution 4.0 International License. 



\section{Managing biological invasions: the cost of inaction}

3 Danish A. Ahmed ${ }^{\mathrm{a}, ¥}$, Emma J. Hudgins ${ }^{\mathrm{b}, \mathrm{c}, \epsilon, \ldots}$, Ross N. Cuthbert ${ }^{\mathrm{d}, ¥}$, Melina Kourantidou ${ }^{\mathrm{e}, \mathrm{f}, \mathrm{g}}$,

4 Christophe Diagne $^{\mathrm{h}}$, Phillip J. Haubrock ${ }^{\mathrm{i}, \mathrm{j}}$, Brian Leung ${ }^{\mathrm{b}}$, Chunlong Liu ${ }^{\mathrm{h}, \mathrm{k}, \mathrm{l}, \mathrm{m}}$, Boris Leroy ${ }^{\mathrm{n}}$,

5 Sergei Petrovskii ${ }^{\mathrm{i}}$, Franck Courchamp ${ }^{\mathrm{h}}$

6

${ }^{\mathrm{a}}$ Center for Applied Mathematics and Bioinformatics (CAMB), Department of Mathematics and Natural Sciences, Gulf University for Science and Technology, P.O. Box 7207, Hawally 32093, Kuwait

${ }^{\mathrm{c}}$ Department of Biology, Carleton University, Ottawa, Ontario, Canada K1S 5B6 ${ }^{\mathrm{d}}$ GEOMAR Helmholtz-Zentrum für Ozeanforschung Kiel, 24105 Kiel, Germany

${ }^{\mathrm{e}}$ Woods Hole Oceanographic Institution, Marine Policy Center, Woods Hole, MA 02543, United States

f Institute of Marine Biological Resources and Inland Waters, Hellenic Center for Marine Research, Athens 164 52, Greece

'University of Southern Denmark, Department of Sociology, Environmental and Business Economics, Esbjerg Ø, 6705, Denmark

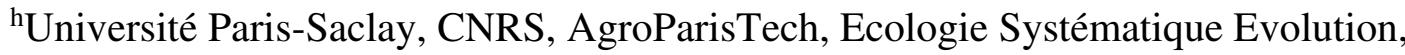
91405, Orsay, France

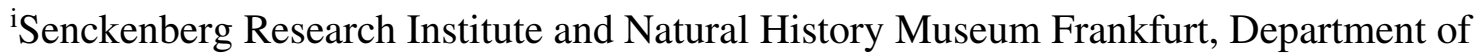
River Ecology and Conservation, Gelnhausen, Germany.

${ }^{j}$ University of South Bohemia in České Budějovice, Faculty of Fisheries and Protection of Waters, South Bohemian Research Center of Aquaculture and Biodiversity of Hydrocenoses, Zátiší 728/II, 38925 Vodňany, Czech Republic

kInstitute of Biology, Freie Universität Berlin, 14195 Berlin, Germany

${ }^{1}$ Leibniz Institute of Freshwater Ecology and Inland Fisheries (IGB), 12587 Berlin, Germany

merlin-Brandenburg Institute of Advanced Biodiversity Research (BBIB), 14195

Berlin, Germany

${ }^{\mathrm{n}}$ Unité Biologie des Organismes et Ecosystèmes Aquatiques (BOREA, UMR 7208), Muséum national d'Histoire naturelle, Sorbonne Université, Université de Caen Normandie, CNRS, IRD, Université des Antilles, Paris, France.

${ }^{\circ}$ School of Mathematics and Actuarial Science, University of Leicester, University road, Leicester, LE1 7RH, UK

${ }^{¥}$ Equivalent contribution

${ }^{€}$ Corresponding author: emma.hudgins@ mail.mcgill.ca 


\section{Abstract}

42 Ecological and socio-economic impacts from biological invasions are rapidly escalating 43 worldwide. While effective management underpins impact mitigation, such actions are often 44 delayed, insufficient or entirely absent. Presently, management delays emanate from a lack of 45 monetary rationale to invest at early invasion stages, which precludes effective prevention.

46 Here, we provide such rationale by developing a conceptual model, based on logistic growth, 47 to quantify the cost of inaction towards invasive alien species under varying time delays and 48 management efforts. Further, we apply the resulting model to management and damage data 49 from a relatively data-rich genus (Aedes mosquitoes). Our model confirms that rapid 50 management interventions following invasion drastically minimise costs, and that higher 51 management investments lead to much steeper cost declines. Further, we identify a 'runaway' 52 point beyond which costs of inaction slowly approach saturation. Any management action 53 during this phase can be considered severely delayed, resulting in substantial losses. For 54 Aedes, we estimated that a management delay of just 20 years could have accrued additional costs of at least US\$ 842 million in 40 years, whereas in the case of no management, inaction 56 costs could have been approximately three-fold higher, totalling US\$2433 million. These results highlight the need for more timely management of invasive alien species by demonstrating how early investments rapidly reduce long-term economic impacts.

Keywords: InvaCost, invasive alien species, logistic growth, socio-economic impacts, 61 prevention and biosecurity, long-term management 


\section{Introduction}

64

65

66

67

68

69

70

71

72

73

74

75

76

Among the countless non-native species that are present worldwide and continue to be introduced (Seebens et al., 2017), a subset of those negatively impact native biodiversity and ecosystems in their novel range, compromise human and social wellbeing and continue to expand their distributions (Walsh et al., 2016; Blackburn et al., 2019; Diagne et al., 2021). Notably, invasive alien species (IAS) can have dramatic impacts on ecosystems (e.g., Shabani et al., 2020; Bellard et al., 2017; Ricciardi \& MacIsaac, 2011), multiple sectors of the economy such as agriculture, fisheries and forestry (Paini et al., 2016; Holmes et al., 2009; Haubrock et al.,this special issue), human health (Shepard et al., 2011; Schaffner et al., 2020) and human and social well-being (Pejchar \& Mooney, 2009; Jones, 2017). Even though a lot of these impacts are not yet fully understood or quantified (Vilà et al., 2010; Kumschick et al., 2015; Crystal-Ornelas \& Lockwood, 2020), the scientific consensus is that IAS impacts - albeit varying in their nature - are massive, growing, and constitute a major driver of biodiversity loss and global change (Simberloff et al., 2013; IPBES 2019; Pyšek et al., 2020; Seebens et al., 2017). As a result, resource management agencies and conservation practitioners worldwide are continuously working to develop management tools - legal, institutional and methodological — to respond to new invasions through the prevention or limitation of spread and the mitigation of impacts (e.g., Hoffmann \& Broadhurst, 2016; Jones et al., 2016).

There are, however, several aspects hindering the effective management of invasive populations (Courchamp et al., 2017. In particular, the justification of management expenditures is a challenge, as management is costly, IAS are numerous and budgets are limited. Even though it is generally assumed that early responses are more cost-effective (Leung et al., 2002; Timmins \& Braithwaite, 2002; Russell et al., 2015), in practice, applied management is often delayed (if implemented at all). The situation is exacerbated by the observation that the IAS proliferation (and hence any noticeable effect from it) is often delayed due to time lags and long transients that are inherent for the invasion dynamics (Crooks, 2005; Francis et al., 2021). Meanwhile, unless these intrinsic time lags are taken into account (and control actions are applied early accordingly), the IAS management is likely to be inefficient (Francis et al., 2021). Preventative management in particular can be seen as a riskier strategy than waiting to control IAS after establishment, because neither its effectiveness, nor the eventual invasion of a given IAS, can be predicted with high certainty (Finnoff et al., 2007). Indeed, although acting sooner can minimize the total amount of money spent in the long-term, in the absence of an adequate appraisal of their ecological and economic impacts, the cost of inaction may be implicitly assumed to be zero, particularly when responding to ecosystem-based impacts with less tangible damage costs. In a system where impacts are not necessarily borne by the same societal entities as those who fund management actions, immediate spending always needs to be strongly justified. In addition, in the existence of budget limitations and multiple other conservation needs, it is always tempting to wait for impacts to be demonstrated, to be realised or even to be severe before investing in management. As such, allocating budgets to the management of populations that have not yet shown tangible, strong impacts may be difficult to justify for decision makers. 
For biological invasions, there is presently a lack of such justification to invest in earlystage management actions. Thus, the objective of this study is to provide quantitative support for early investment by showing that management becomes increasingly costly with implementation delay. We focus on a theoretical demonstration, but use both mathematical modelling and empirical data from the InvaCost database - the most comprehensive and upto-date dataset of costs caused by IAS globally (Diagne et al., 2020a, 2020b).

Our central hypothesis and model assumption is that the cumulative costs of both damage and management of IAS follow a logistic curve with time. This assumption follows the well-accepted "invasion curve" (Leung et al., 2002; Lodge et al., 2016), which predicts that the area invaded by an IAS initially increases slowly, but then accelerates, and eventually reaches a plateau (Fig. 1). While the precise shape of the curve may depend on case-specific details (e.g. on the environmental properties), we mention here that the logistic growth of the invaded area is shown theoretically in the context of metapopulation dynamics (Amarasekare 1998). If we assume that impact is proportional to the area invaded (Parker et al., 1999), the costs associated with a single IAS should follow a similar logistic curve.

While no one model can describe all invasion impact patterns perfectly, we show the utility of the invasion curve for describing the cost cumulation patterns of individual IAS. Further, we use the fitted curves to derive parameters for cost growth rates and cost carrying capacities, which allow a quantification of the cost of delayed management for any given management delay period. In this way, we provide a framework for the valuation of foregone damage costs, which can be used as an imperative to manage species invasions as proactively as possible.

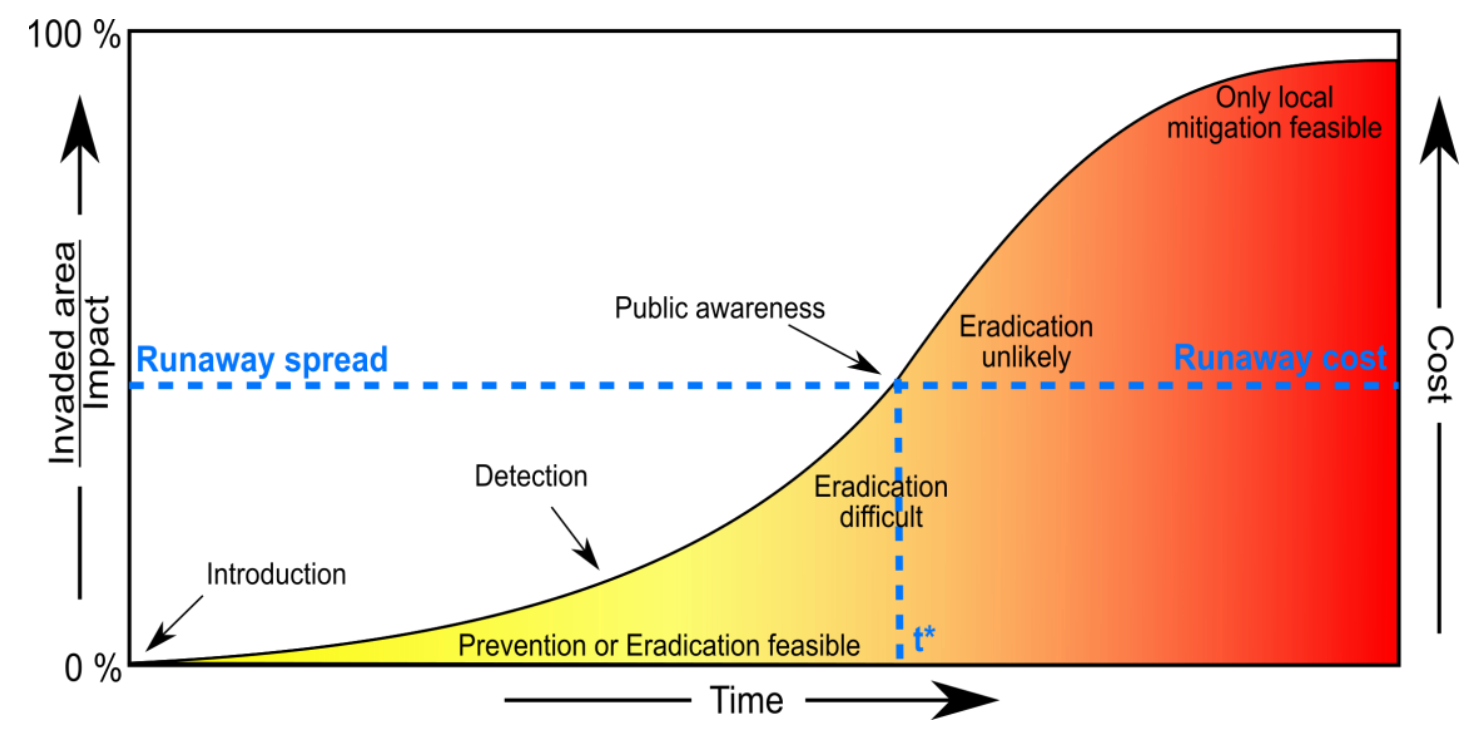

Figure 1. The classical invasion curve. This relationship displays a generalized invasive alien population response over time, after its introduction and establishment into a new environment. As the population expands and spreads, the area invaded (reported as a percentage of its total invaded area), its impact (damage costs), and its management costs increase following a logistic curve. Management costs, invaded area, and impact all grow at increasing rates until $t^{*}$, where they reach their maximum rates (which we call the 'runaway' point, see section 3.5). Adapted from Invasive Plants and Animals Policy Framework, Victorian government, 2010. 
At the time of initiating the study, the InvaCost database includes 9,823 entries from systematic and opportunistic literature searches conducted primarily in English, and altogether in 15 languages (Diagne et al., 2020b; Angulo et al., 2021). This database captures reported economic costs associated with IAS in their novel range (incurring costs from management, damage and losses), including species that may become established in the future (incurring costs from prevention and early detection and rapid response) in a specific area. These data are described with a number of key database descriptors (over 60 in the latest InvaCost version 3.0, see https://doi.org/10.6084/m9.figshare.12668570 for complete details) and standardised against a single currency (2017 US\$). These descriptors include, among other things, the cost type ("Type of cost merged"), which groups costs into three distinct categories: (a) "Damage" referring to damages or losses incurred by the invasion (e.g. costs for damage repair, resource losses, medical care), (b) "Management" comprising any expenditures dedicated to prevent, limit and/or mitigate invasion impacts (e.g. monitoring, prevention, control, education, eradication) and (c) "Mixed" including indistinguishable damage and management costs (cases where reported costs were not clearly separable from the aforementioned cost types categories). We considered all types of damage costs, but only post-invasion management costs, in order to eliminate preventative management. This was done using the "Management_type" column of the database by selecting the "Postinvasion_management" category therein. We further filtered our dataset to examine only costs incurred at larger scales, using only "Country" and "Site" spatial scales from the "Spatial_scale" column, and focussed on only costs deemed to be of "High" reliability in the "Method_reliability" column. We also removed any extrapolated (unobserved) costs by limiting our search to "Observed" costs in the "Implementation" column.

For the consistency and comparison in data used, all costs in the original database were 'expanded' so that cost entries could be considered on an annual basis. This means that single cost entries spanning multiple years (e.g. \$10 million between 2001 and 2010) were divided into distinct entries according to their duration (e.g. \$1 million for each year between 2001 and 2010 corresponding to ten entries in the expanded database). Expansion was done using the expandYearlyCosts function of the 'invacost' R package (Leroy et al., 2020), which repeats the annual cost for each database entry according to the estimated time range of impacts provided with each reference in the InvaCost database.

To illustrate the logistic growth of economic costs, we used species-specific datasets from the InvaCost database to model the cumulative yearly costs with time. Ideally, we would have shown the applicability of this approach for the majority of IAS. However, we were limited by the number of species with sufficient temporal cost data. Our species-specific approach was thus restricted to genera with both $>10$ independent post-colonial (after year 1500) cost estimates from InvaCost and a lack of large gaps in cost records over time (7 genera in total: 3 for damage costs: Ambrosia, Callosciurus, and Procyon, 3 for management costs: Anoplophora, Cenchrus, and Salvinia and 1 genus with adequate records for both damage and management costs: Aedes). 
After establishing that the cumulative damage and management costs of IAS can be represented by the invasion curve, we formalized the calculation of the cost of management delay by calculating the total cost of damage and management from the start of the invasion to any given year, under any given management delay scenario. For illustration purposes, we applied this calculation to Aedes spp. - where management and damage curves are well defined - under a range of management delay scenarios (Appendix 1).

\section{Modelling the cost of delayed management}

182 Several cost-related terms are used in the following sections, which we highlight here for 183 ease of interpretation. First, we define the cumulative cost of management, cumulative cost of 184 damage, and the total cumulative cost (cumulative cost of management + cumulative cost of 185 damage) as the sum of all costs incurred by an IAS since its first reported cost. Second, we 186 define the instantaneous cost of damage and instantaneous cost of management as the costs incurred by a given IAS in a given year or timestep. Third, we define the marginal cost of damage and the marginal cost of management as the respective change in the cumulative damage and management costs of a given IAS between two timesteps (which we model as being equivalent to the instantaneous costs of damage and management, respectively), and the total marginal cost as the change in the total cumulative cost of a given IAS between two timesteps (i.e., the total cumulative cost for this year minus the total cumulative cost of the previous year).

\subsection{Proactive management}

We first assume proactive management, i.e biosecurity measures such as prevention, early detection and rapid response, which we assume here for the purposes of this modelling exercise as infallible (i.e., $100 \%$ effective at preventing future damage costs by a given IAS). One of the simplest mathematical formulations of biosecurity is a constant cost per unit time, I (investment) to prevent the cost of an invasion; which is worth paying if:

$$
\frac{d B}{d t}<\frac{d C}{d t} \Leftrightarrow I<r C\left(1-\frac{C}{K}\right)
$$

where $B$ is the unit of biosecurity invested, $C(t)$ is the cumulative damage costs of an invasive alien species, $r$ is the intrinsic growth rate of damage costs and $K$ is the carrying capacity of those costs.

The difference between the two primitives (i.e., the difference between the investment cost and the damage cost at time $t$ ) is simply the total amount lost in year $t$ by not using

211 biosecurity. Since solutions for proactive management $(t \leq 0)$ are mathematically trivial, we

212 will only focus on reactive management, i.e., management that starts after an invasion has 213 started.

\section{$214 \quad 3.2$ Reactive management}


215 Following the classical invasion curve (Fig. 1), we hypothesize that the cumulative damage

$216 \operatorname{cost} C(t)$ of an invasive alien species displays logistic growth:

$217 \quad \frac{d C}{d t}=r C\left(1-\frac{C}{K}\right), \quad C(0)=C_{0}$

218 and therefore can be modelled using a classical logistic curve as a function of time:

$219 C(t)=\frac{K}{1+\left(\frac{K}{C_{0}}-1\right) e^{-r t}}$

220

221

222

223

224

225

226

227

228

229

230

231

232

233

234

235

236

237

238

239

240

241

242

243

244

245

where $C_{0}$ is the initial cumulative damage cost, $K$ is the maximum cost, to which we, for convenience, refer to as the cost carrying capacity, and $r$ is the intrinsic growth rate of damage costs.

We assume a reactive management action that decreases the impact of an invasion, and therefore its damage cost. The management itself has an expenditure $M(t-\tau)$ which can be delayed by $\tau$ years. Since the cumulative management cost is expected to also depend on the invasion stage, it can also be modelled as a logistic curve, with an intrinsic growth rate $r_{M}$ that can be different than the growth rate of damage costs. In addition, a reasonable assumption is that the cumulative management cost is a constant proportion of the damage cost, and therefore has a cost carrying capacity $K_{M}=\gamma K$ and an initial management cost $\mathrm{M}(0)=M_{0}=\gamma C_{0}$, where $\gamma$ is a parameter that quantifies management effort and lies between 0 and 1 inclusive. Therefore, one can write:

$M(t-\tau)=\gamma \cdot \frac{K}{1+\left(\frac{K}{C_{0}}-1\right) e^{-r_{M}(t-\tau)}} \cdot H(t-\tau), \quad M(0)=M_{0}$

where $H(t-\tau)$ is a unit step function with value 0 if $t<\tau, \frac{1}{2}$ if $t=\tau$ and 1 if $t>\tau$ (also known as the Heaviside function). Note that in eqn. 5, $\tau=0$ corresponds to a special case where there is no delay in management with cumulative cost value $M(t)$. Also, with this formulation, $\gamma=1$ can be considered as an upper limit where management effort can theoretically achieve $100 \%$ efficiency (i.e., reduce damage costs to zero), at a cost equivalent to the damage cost. In practice, this value (which implies functional eradication) is rarely reached even in the case of intensive management efforts.

\subsection{Cost of inaction}

If management is introduced at some delayed time $\tau$, the total amount of reduced losses $\varphi$ is given by the difference between cumulative damage and management costs:

$\varphi(t, \tau)=C(t)-M(t-\tau)=\frac{K}{1+\left(\frac{K}{C_{0}}-1\right) e^{-r t}}-\gamma \cdot \frac{K}{1+\left(\frac{K}{C_{0}}-1\right) e^{-r_{M}(t-\tau)}} \cdot H(t-\tau)$

In the case where management is not delayed, the losses amount to: 
$\varphi(t, 0)=C(t)-M(t)=\frac{K}{1+\left(\frac{K}{c_{0}}-1\right) e^{-r t}}-\gamma \cdot \frac{K}{1+\left(\frac{K}{c_{0}}-1\right) e^{-r_{M} t}} \cdot H(t)$

247 We expect the total amount of losses to be greater in the case where management is delayed,

248 and therefore that $\varphi(t, \tau)>\varphi(t, 0)$ at all times.

249 The 'cost of inaction' function $(\Phi)$ is the potential savings one can acquire due to earlier

250 management intervention, i.e., the cost difference between the total losses in eqn. 6-7, written 251 as:

252

$\Phi(t, \tau)=\varphi(t, \tau)-\varphi(t, 0)=M(t)-M(t-\tau)$

which can be expressed as:

$\Phi(t, \tau)=\gamma\left(\frac{K}{1+\left(\frac{K}{C_{0}}-1\right) e^{-r_{M} t}} \cdot H(t)-\frac{K}{1+\left(\frac{K}{C_{0}}-1\right) e^{-r_{M}(t-\tau)}} \cdot H(t-\tau)\right)$

256 Note that eqn. 9 depends on the intrinsic growth rate of cumulative management costs $r_{M}$, and 257 not $r$.

\subsection{Properties of the cost of inaction function}

259 The cost of inaction function (eqn. 9) evaluated at time $t=0$, with management delay at

260 some later time $\tau>0$, reduces to:

$261 \quad \Phi(0, \tau)=\frac{1}{2} \cdot \frac{\gamma K}{1+\left(\frac{K}{C_{0}}-1\right)}$

262 whereas if management is introduced at $\tau=0$, then $\Phi(0,0)=0$. Also, at some fixed time $t>$ 2630 , with no management action $(\tau \rightarrow \infty)$, one gets:

$264 \Phi(t, \tau \rightarrow \infty)=\gamma\left(\frac{K}{1+\left(\frac{K}{c_{0}}-1\right) e^{-r_{M} t}}\right)$

265 and for sufficiently large but finite time, this converges to:

$266 \Phi(t, \tau \rightarrow \infty)=\gamma K$

267 which is precisely the level where the cost saturates. Finally, for a fixed but finite

268 management delay $\tau>0$, the cost of inaction in the long-term $(t \rightarrow \infty)$ reduces to zero i.e., $269 \Phi(t \rightarrow \infty, \tau)=0$. In summary, the long-term cost dynamics differ depending on whether

270 management is imposed or not, either leading to null costs (of inaction), or saturating at a 271 constant level, respectively. 
273 The logistic curve models for cumulative damage and management costs, i.e., eqn. 4-5,

274 saturate at the cost carrying capacities $K$ and $K_{M}$ (Fig. 2a,c). The implication is that marginal

275 damage and management costs decay exponentially in the long-term, eventually reaching

276 zero (Fig. 2b). In a more realistic scenario, one may expect damage and management costs to

277 be continuously reported. However, based on empirical findings, these costs appear to be

278 several orders of magnitude smaller than the corresponding largest reported

279 damage/management cost, likely due to dwindling effort in cost detection and management,

280 and saturation of the invasible range (Fig. 1). As a result, any additional contributions to the

281 cumulative costs of damage and management would be negligible, and therefore can be

282 reasonably modelled at a 'near' saturation level (as demonstrated later for Aedes spp. in Fig.

283 6, see also Ahmed et al., this special issue).

Fig. 2d illustrates the cost of inaction function $\Phi(t, \tau)$ given by eqn. 9 , which evaluates the difference in cost between two distinct scenarios: one where management is

286 introduced instantly (at time $\tau=0$ ), and one where management is delayed by time $\tau$. In the 287 special case where no action is taken (considered as a theoretical limit $\tau \rightarrow \infty$, red curve, Fig.

$2882 \mathrm{~d}$ ), the expenditure continues to accrue and saturates at the carrying capacity of management 289 costs $K_{M}=\gamma K$. The red marker in plot (d) is a 'runaway' point (or point of inflection, see 290 Fig. 1) which occurs at time $t^{*}=\frac{1}{r_{M}} \ln \left(\frac{K}{C_{0}}-1\right)$ with a corresponding cost of inaction value

291 at half the management cost carrying capacity i.e., $\Phi^{*}=\frac{1}{2} K_{M}=\frac{1}{2} \gamma K$, where the cost

292 transitions from fast accrual $\left(t<t^{*}\right)$ to slower accrual $\left(t>t^{*}\right)$.

In our model, we found that increased delay (larger $\tau$ ) led to greater expenditures, as expected. Generally, once management is introduced, the cost of inaction 'dips' (due to a considerable initial management expenditure), and in the long-term, decays exponentially leading to null costs (of inaction). However, the cost dynamics shortly after management

297 onset depend heavily on the delay time, specifically when the cost of inaction approaches saturation. If delayed management is implemented at an early stage, expenditures still may continue to increase, eventually reaching a peak with subsequent decay (e.g. Fig. $2 \mathrm{~d}$ for $\tau=$ 20). In contrast, if management is implemented after a time where the cost of inaction has 301 almost saturated, then expenditures will only decrease, and at a much faster rate (e.g. Fig. $2 \mathrm{~d}$ 302 for $\tau=50,60)$. Interestingly, a faster reduction does not outweigh the effects of severely 303 delayed management, with null expenditures reached much quicker with earlier management. 

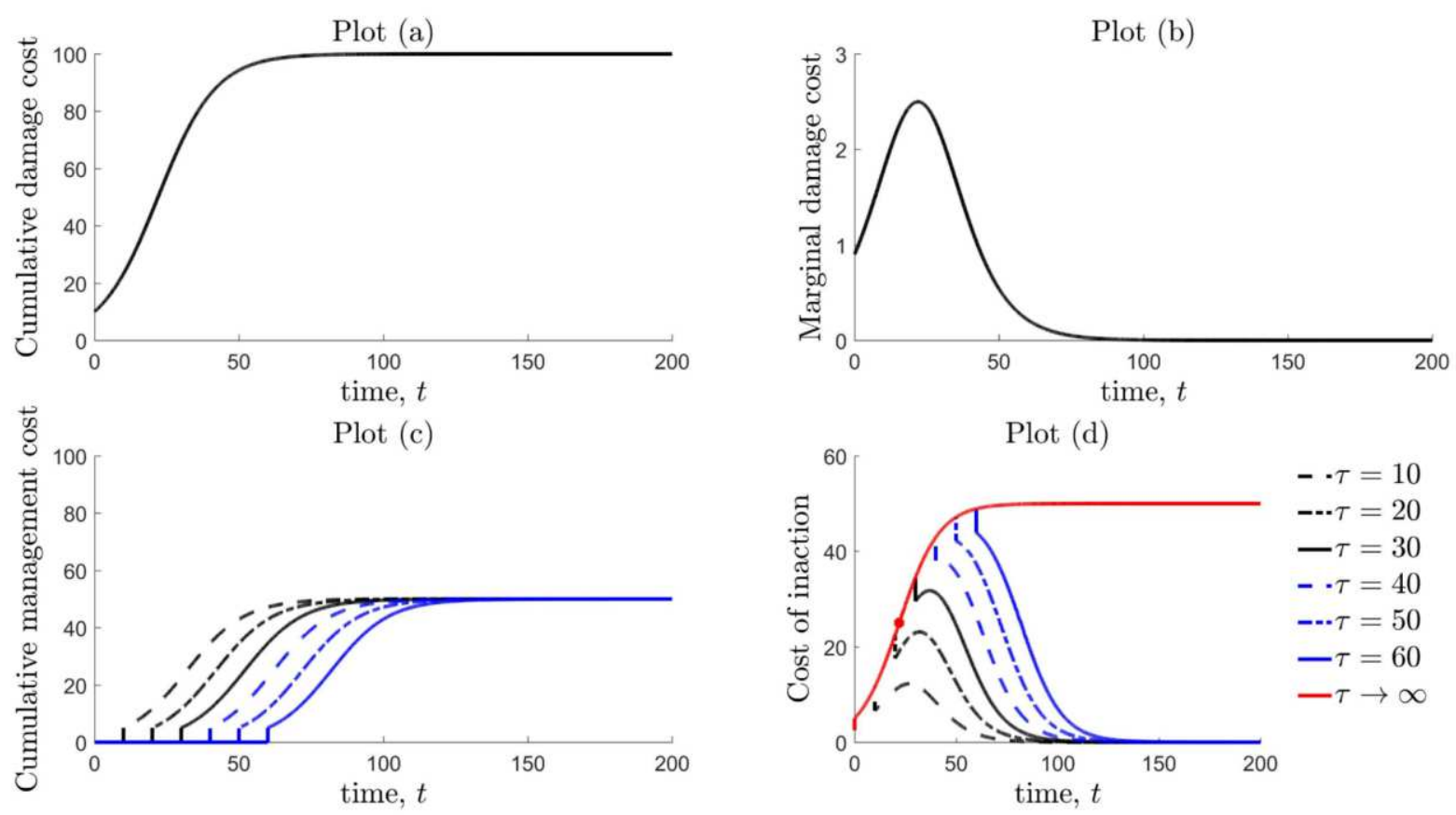

Figure 2: The impact of management delay. Plot (a) shows cumulative damage costs $C(t)$, which are modelled using a logistic curve, see eqn. 4. Plot (b) shows the instantaneous damage costs as a function of time (i.e., the marginal cost for each additional year of damage from eqn. 3). Plot (c) shows cumulative management costs $M(t-\tau)$, which are proportional to damage costs according to factor $\gamma$, and delayed by some time $\tau$, see eqn. 5. Plot (d) shows the cost of inaction $\Phi(t, \tau)$ over time, see eqn. 9. The red curve illustrates a special case where no action is ever taken, all others represent different scenarios of increasingly delayed management. The red marker is the point of inflection or 'runaway point'. Parameter values in all cases: Damage cost carrying capacity $K=100$, Growth rate $r=r_{M}=0.1$, Initial damage cost $C_{0}=10$, Management effort $\gamma=$

3130.5 , Management cost carrying capacity $K_{M}=\gamma K=50$, Management delay $\tau$ varied. Figure legend only

314 applies to plots (c) and (d).

We also found that higher management effort $\gamma$ led to steeper declines in the cost of inaction after management implementation (Fig. 3). However, increased management effort

317 led to higher peaks in the cost of inaction due to the relationship between management effort and management cost. 

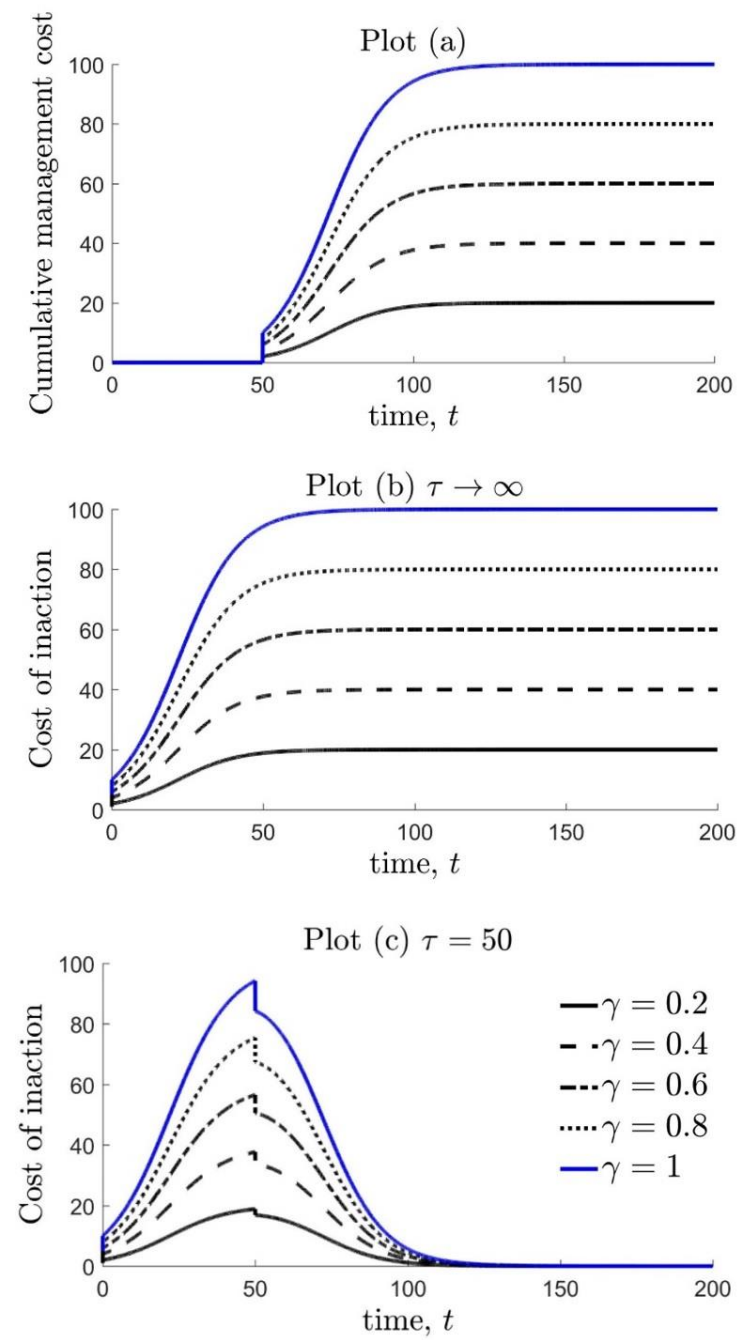

320 Figure 3: The impact of management effort. Plot (a) shows management cost curves over time, with a logistic form and a cost carrying capacity $K_{M}=\gamma K$, proportional to the damage cost carrying capacity $K$, with management effort quantified by parameter $\gamma$, see eqn. 5. They are equivalent to plots of Fig. 2c. Plot (b) shows the associated cost of inaction for an infinite management delay (equivalent to the red curve of Fig. 2d). Plot (c) demonstrates the impact of management effort on the cost of inaction for a delay of $\tau=50$. The higher the management costs, the more costly due to delayed management. Parameter values: Cost carrying capacity $K=$ 100 , with management effort $\gamma$ varied. Intrinsic growth rate $r=r_{M}=0.1$, Initial damage $\operatorname{cost} C_{0}=10$, Management delay $\tau=50$.

Upon examining the interactive behaviour of the model parameters (Fig. 4), we found that longer management delays allowed a wider range of $r_{M}$ values to lead to large costs, whereas at low management delays, only small $r_{M}$ values led to large costs. Across management delays, larger $K$ values led to greater costs of inaction. 

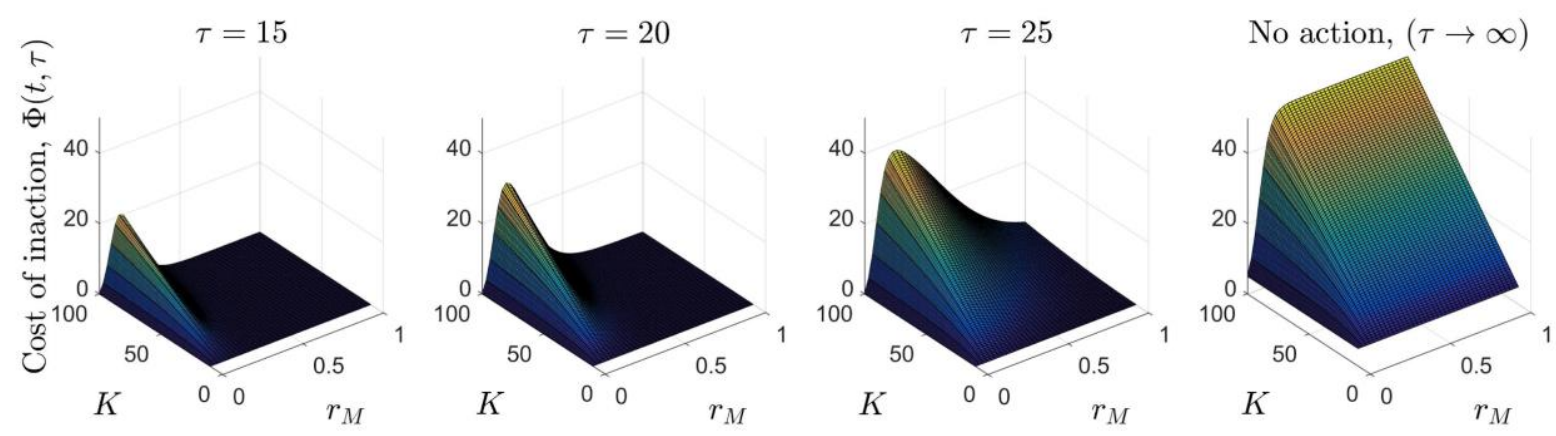

Figure 4: Snapshots of the cost of inaction at time $t=30$. Management is introduced at different times $\tau$. The limiting case $\tau \rightarrow \infty$ represents the case where management is not introduced, i.e., no action is taken. Parameter values: Initial damage $\operatorname{cost} C_{0}=10$, Management effort $\gamma=0.5$.

\section{Empirical results}

\section{4.1. Damage and Management curves}

338 All of our logistic fits were very strong across genera $\left(R^{2}>0.9\right.$, Table 1$)$. We found that 339 raccoons (Procyon) and squirrels (Callosciurus) had the highest $r$ values, while longhorn 340 beetles (Anoplophora) and sandburs (Cenchrus) had the highest $r_{M}$ values (Fig. 5). Aedes, 341 Anoplophora and Ambrosia spp. reached very high damage and/or management costs.

342 Anoplophora had both high $r_{M}$ and $K_{M}$ values. While all economic impact data are subject to 343 time lags in invasion and detection (Crooks, 2005), we found greater support for lagged occurrence of damage costs compared to management costs when collating InvaCost data with the sTwist database for first records of invasions (Seebens et al., 2020, Table 1). The initial damage cost is found to be significantly lower than the cost carrying capacity (approx. $10 \%$ or lower), and varies across genera. This does not hold for initial management costs, which can be relatively much higher, for e.g. Salvinia (floating fern). The "cost lag" column provides the time between the first known record of the IAS anywhere outside of its native range (from the sTwist Database, Seebens et al., 2020) and the first record within InvaCost.

Table 1. Logistic modelling results for (A) cumulative damage costs and (B) cumulative management costs. Note that these costs were modelled separately without assuming proportionate cost carrying capacities. Growth rates: low $r, r_{M}<0.1$ (yellow), intermediate $0.1<r, r_{M}<0.3$ (orange), high $r, r_{M}>0.3$ (red). Cost carrying capacity: low $K, K_{M}<100$ (yellow), intermediate $100<K, K_{M}<1000$ (orange), high $K, K_{M}>1000$ (red). The "\# estimates" column provides the number of independent cost references provided in the InvaCost database with which the curves were derived. The parameter values are rounded to two decimal places, but the initial cost to carrying capacity ratio is computed using values to a higher degree of accuracy, see Appendix 2.

\begin{tabular}{|l|l|l|l|l|l|l|l|l|}
\hline & Genus & $\begin{array}{l}\text { Cost } \\
\text { intrinsic } \\
\text { growth rate }\end{array}$ & $\begin{array}{l}\text { Cost } \\
\text { carrying } \\
\text { capacity }\end{array}$ & Initial cost & $\begin{array}{l}\text { Initial cost } \\
\text { to carrying } \\
\text { capacity } \\
\text { ratio (\%) }\end{array}$ & $\begin{array}{l}\text { Cost lag } \\
\text { (year) Time } \\
\text { of cost onset } \\
\text { after } \\
\text { introduction } \\
\text { (years) }\end{array}$ & $\begin{array}{l}\text { \#No. of } \\
\text { independent } \\
\text { cost } \\
\text { estimates }\end{array}$ & $\begin{array}{l}\text { Coefficient of } \\
\text { determination } \\
R^{2}\end{array}$ \\
\hline
\end{tabular}




\begin{tabular}{|c|c|c|c|c|c|c|c|c|}
\hline & & $r$ & K & $C_{0}$ & $C_{0} / K(\%)$ & & & \\
\hline \multirow{4}{*}{$\begin{array}{l}\text { A. Cumulative } \\
\text { damage costs }\end{array}$} & Ambrosia & 0.03 & 7094.85 & 463.61 & 6.53 & 0 & 196 & 0.941 \\
\hline & Callosciurus & 0.40 & 2.07 & 0.05 & 2.21 & 66 & 32 & 0.997 \\
\hline & Aedes & 0.24 & 19183.48 & 1450.54 & 7.56 & 0 & 134 & 0.997 \\
\hline & Procyon & 0.34 & 102.35 & 0.36 & 0.35 & 33 & 21 & 0.999 \\
\hline & & $r_{M}$ & $K_{M}$ & $M_{0}$ & $M_{0} / K_{M}(\%)$ & & & \\
\hline \multirow{4}{*}{$\begin{array}{l}\text { B. Cumulative } \\
\text { management } \\
\text { costs }\end{array}$} & Anoplophora & 0.44 & 1679.51 & 194.26 & 11.57 & 0 & 13 & 0.994 \\
\hline & Cenchrus & 0.46 & 10.21 & 0.01 & 0.12 & 8 & 106 & 0.996 \\
\hline & Aedes & 0.16 & 2474.19 & 163.11 & 6.59 & 0 & 97 & 0.966 \\
\hline & Salvinia & 0.17 & 1.13 & 0.24 & 21.23 & 0 & 13 & 0.956 \\
\hline
\end{tabular}
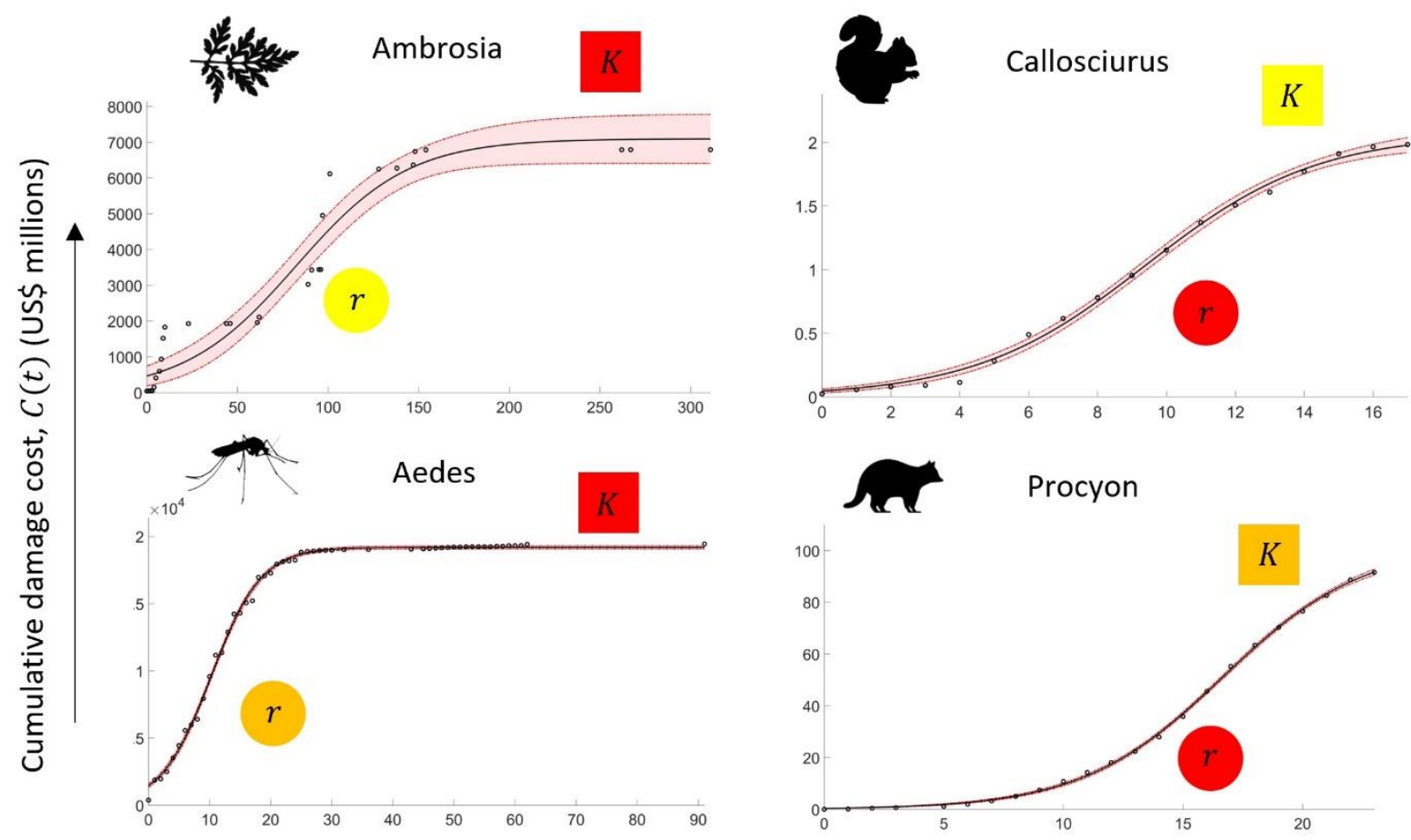

Time since first cost, $t$ (years) 


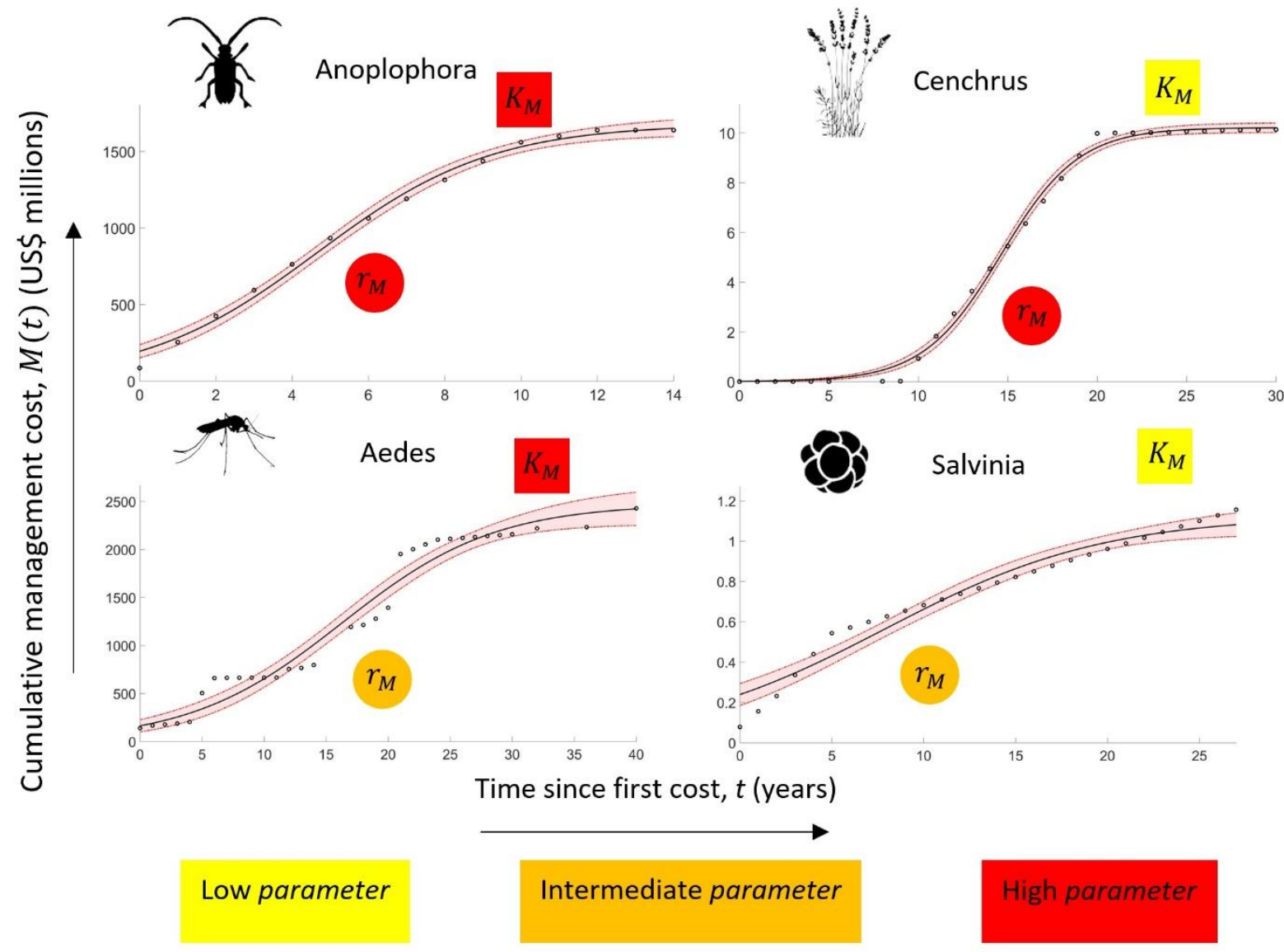

361 Figure 5. Model fitting of cumulative damage costs (top) and cumulative management costs (bottom) using a logistic curve, for different invasive alien species. The red shaded areas around the curves represent $95 \%$ confidence regions indicating the range of predicted cumulative costs. The estimated logistic model fit parameters are given in Table 1. The range for low/intermediate/high parameter values are given in the caption of Table 1 using the same colour scheme. High values of the intrinsic growth rate $\left(r\right.$ or $\left.r_{M}\right)$ illustrate species for which costs increase rapidly; high values of the cost carrying capacity $\left(K\right.$ or $\left.K_{M}\right)$ illustrate species for which costs eventually saturate at high values. Dots represent annual total costs. Note that the scales differ across subplots.

\subsection{Case study for Aedes spp.}

370 We illustrate the utility of our model in its ability to calculate the net present benefit of acting immediately, in terms of the foregone losses for each year of management delay, using the genus for which we have good empirical data on both damage and management costs over time (Aedes spp.; see Appendix 1 for detailed calculations). Aedes have many decades of damage cost data that display clear saturation at a very high cost, with an intermediate cost intrinsic growth rate (Fig. 6a). The management costs to date for this genus are much lower (we estimate a management effort of $\gamma=0.13$ ), but also generally tend to follow a logistic curve (Fig. 6b). By synthesizing the outputs of both of these models, we can calculate the cost of inaction at the global scale for any given management delay using eqn. 9 (see Fig. 6c). 

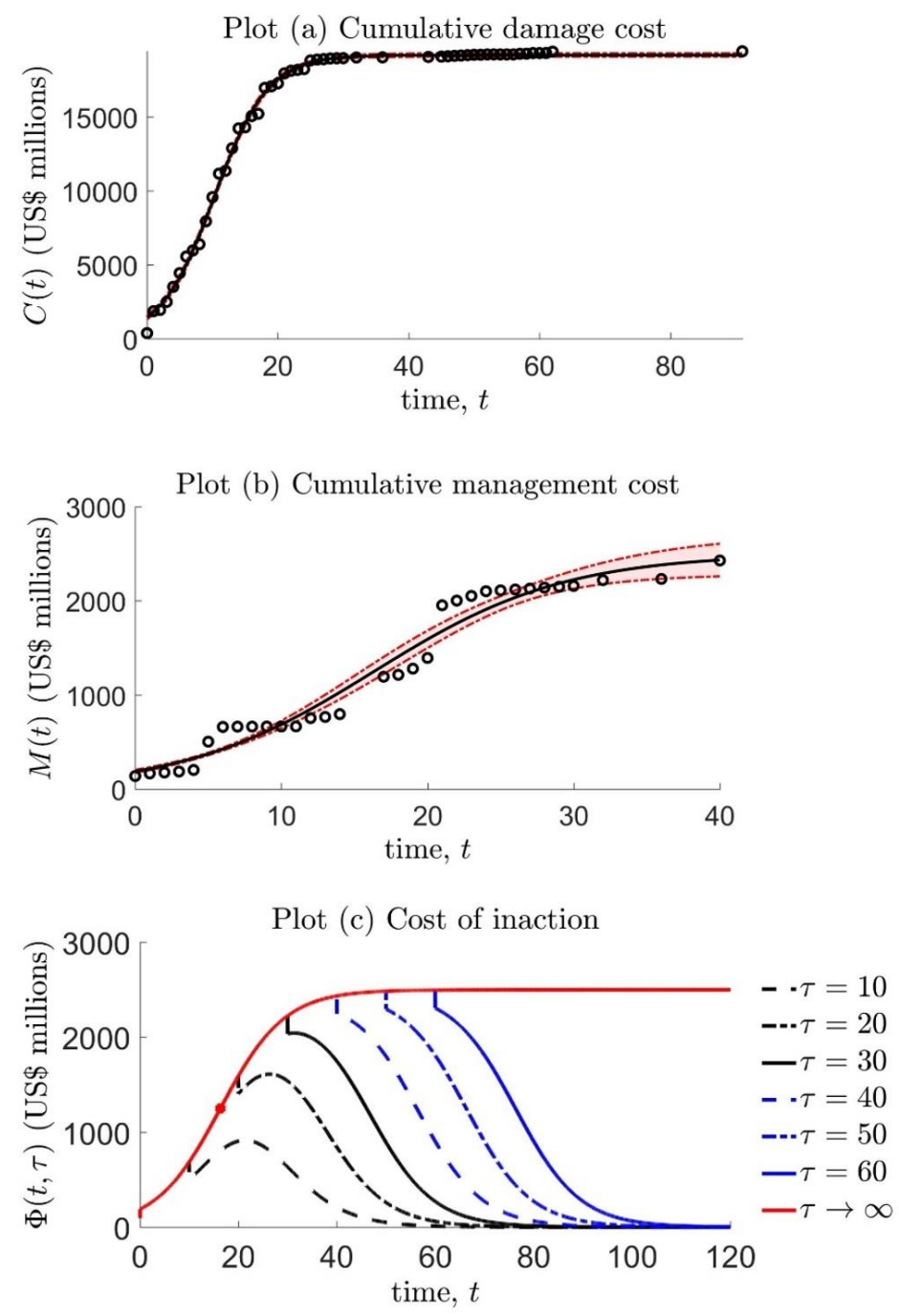

380 Figure 6: Plot (a) Cumulative damage cost for Aedes. Parameters: Initial damage cost $C_{0}=1450.54$, cost 381 carrying capacity $K=19183.48$, intrinsic growth rate $r=0.24$, coefficient of determination $R^{2}=0.997$. Plot (b) Cumulative management cost for Aedes. Parameters: Initial management cost $M_{0}=\gamma C_{0}=188.86$, cost carrying capacity $K_{M}=\gamma K=2497.63$, where $\gamma=0.13$ quantifies management effort, intrinsic growth rate $r_{M}=0.15, R^{2}=0.965$. Red shaded area represents a 95\% confidence region. Plot (c) shows the cost of inaction for Aedes, with management delay $\tau$. The red marker is the runaway point which occurs at $\left(t^{*}, \Phi^{*}\right)=$ $(16.33,1248.86)$. Note that the estimated parameters for management costs differ from those reported in Table 1 , as here it is assumed that cost carrying capacities are directly proportional. Also, the parameter values reported here are rounded to two decimal places, but all computations use estimated parameter values to a higher degree of accuracy, see Appendix 2.

390 For instance, after 40 years from the first reported damage cost, total costs incurred due to 391 this genus following a 20-year management delay would amount to \$17.6B worldwide, while immediate management would lead to only $\$ 16.7 \mathrm{~B}$ in costs. The cost of inaction is the difference between these two costs, estimated at $\sim \$ 842 \mathrm{M}$. In contrast, the cost of inaction in the case of no management action can be significantly higher, approximately three-fold totalling \$2433M, and in the long-term saturating to \$2497M. See Appendix 1 for details of the calculation, with accurate parameter values listed in Appendix 2. We further estimate a 'runaway point' at $t^{*}=16.3$ years, that is the transition point beyond which the cost of inaction begins to accrue at a slower rate, eventually saturating at a maximum value which is 
precisely the long-term cost in the scenario where the genus is never managed. As such, the greatest cost reduction comes from managing in the first $\sim 15$ years after its arrival. With this modelling framework, we can estimate multi-billion dollar additional global costs for neglecting to begin management of mosquito invasions.

\section{Implications for management}

Our work highlights that failing to begin managing an invasion can quickly lead to immense costs. Under the assumptions of our model, in the absence of any management, the cost of inaction itself has a logistic shape (see red curve in Fig. 2d), as has been shown for damage costs across a range of genera and habitat types considered in the InvaCost database (Ahmed et al., this special issue). Therefore, the cost of inaction increases exponentially prior to a certain threshold time, after which it eventually saturates at a high level. This means not only that IAS costs can quickly increase to unbearable amounts, but also that they may initially be deceitfully slow to accrue, therefore not signaling to policy makers the urgency to invest in management. Indeed, during this initial time period, the willingness to allocate funds to IAS management may be low due to the lack of perceived risk or impact detection (Finnoff et al., 2007). However, as we have shown here, these costs can inflate suddenly and potentially overwhelm major sectors of the economy.

Our work defines a crucial window of management opportunity - before the inflection point of the cost of inaction curve in the absence of management. Prior to this 'runaway point', the cost of inaction grows substantially from a small value, meaning that the cost paid each year for management delays quickly becomes very large (solid line, Fig. 2d). Beyond this point, the growth in the cost of inaction slows, and in the long-term reaches a constant maximum, implying that each successive year of waiting has the same maximum cost. As such, we can show that when management is less costly than damage $(\gamma<1)$ : (i) initiating management at any time can reduce the total cost of a given IAS over a long-time horizon, but importantly, (ii) there is a critical time window within which initiating management action can lead to large savings over short time horizons.

The exact length of this window of opportunity depends not only on the cost of management, but also on the damage and management cost curve parameters $K$ and $r_{M}$. In turn, these parameters are inherently affected by, for example, the taxonomic grouping of IAS. We found that larger-bodied IAS such as raccoons (Procyon) and squirrels (Callosciurus), and those that could easily be transported as hitchhikers such as Anoplophora and Cenchrus, had higher $r$ values. This may reflect their greater dispersal ability, or capacity to become entrained in anthropogenic vectors to spread. While empirical data limitations meant that we were only able to fit parameters to a small number of genera, we predict that other rapidly spreading invaders, such as ballast water/hull contaminants (e.g. mollusks and copepods; Lin et al., 2020) may have high cost growth rates $r$. In contrast, genera similar to Aedes and Ambrosia spp. that may not necessarily disperse rapidly at continental scales, but have potential for triggering significant costs, could exhibit high cost carrying capacities $K$ in spite of low cost growth rates. We found that Anoplophora had high $r$ and $K$ values, suggesting it has both a large capacity for damage and a fast growth in costs. These patterns 
would likely be similar for the fall armyworm (Spodoptera frugiperda), which has spread rapidly throughout Africa and Asia with high economic impacts (Abrahams et al., 2017). Other species we suspect will show this pattern are the Asian hornet Vespa velutina and the lionfish Pterois volitans, as they are among the fastest spreaders in terrestrial and marine realms, respectively, and are also known to have very high management and/or damage impacts (Barbet-Massin et al., 2020; Diagne et al., 2020).

However, we acknowledge that many IAS may not have any reported economic costs at all, let alone costs that conform to a logistic curve. IAS impacts are often hard to quantify and monetize (Charles \& Dukes, 2008), with many economic losses therefore going unreported due to a suite of biases or limited capacity to capture them (Bellard \& Jeschke, 2016). The data we selected for this analysis were chosen based on the availability of consistent cost reporting through time by multiple independent sources. While this resulted in a limited sample of IAS suitable for our analysis, this approach was necessary given the lack of cost information for most species at sufficient temporal resolution. Although this work should serve primarily as a theoretical demonstration, where estimated, the costs of inaction were found to be striking. An additional limitation of this study is that, with the exception of the parameterization of management effort for Aedes (equivalent to $13 \%$ of the damage costs), it does not consider management efficiency. Future research should address this flaw and focus on empirical validation, where the suitability of this model is tested across multiple taxa, habitats, and costs from different sectors of the economy. This calls for more effort into estimating and reporting costs in a standardized way (Diagne et al., 2021). Although it may seem intuitive that management is cost-efficient at preventing higher damage costs, we recognize that it can be dependent on the efficiency of management. However, it is currently impossible with the (poor) data available to factor in management efficiency in a reliable manner. Such an endeavour would require data on the damage cost of species under very similar conditions of management and lack of management, which do not exist to our knowledge.

While we were limited in the data and species suitable for our analysis, it is important to acknowledge how this may have impacted our results. Firstly, given the general tendency to research and record species with higher costs for both management and damage, our data are likely skewed to highly damaging species and species requiring costly management. For the same reason, we may have not fully captured the initial, lower costs of each genus. Further, due to lags in IAS detection along with their impacts (Essl et al., 2011), the actual occurrence of impacts is likely somewhat earlier on the timelines, compared to the ones we report in this study, and is variable across species and invaded countries (proxied by 'cost lag' column of Table 1, Seebens et al., 2020). Furthermore, our cost saturation estimations could reflect delays in more contemporary cost reporting, and do not preclude the possibility of future spikes in cost due to range expansions of these IAS (Louppe et al., 2019) or advances in cost quantification methods, and should therefore be interpreted with caution. Finally, the costs incurred are subject to country-level differences considering, for example, the importance of certain industries (Paini et al., 2016), the different research capacity, effort and funding landscapes, the suitability of habitat for each IAS (Parker 1999), and other socioeconomic or environmental factors across countries. 
It is also worth noting that while our analysis was done on selected species and the costs that were available for those, it is likely that in many cases biosecurity measures and other proactive measures can be rendered even more cost effective when several species are managed simultaneously. For instance, airport quarantine and interception services deal with very large lists of potential invaders such as insect species, with only marginal costs for each additional species (Lougheed et al., 2007). Aquatic biosecurity measures such as Check Clean Dry campaigns similarly target a range of taxa indiscriminately (e.g., bivalves, crustaceans and macrophytes; Anderson et al., 2015; Shannon et al., 2018; Coughlan et al., 2020). Transport legislation such as wood-packing material treatment protocol ISPM15 can also help minimize IAS risk at that pathway level (Leung et al., 2014).

\section{Conclusion}

Mathematical modelling is an important part of the theoretical ecology toolbox as well as of ecological research more generally; it also plays an important role in informing ecosystem managers, decision-makers and stakeholders. There are many well-documented cases where even simple, conceptual models made a direct and significant impact on ecosystem management, in particular helping to find an efficient and cost-saving strategy (DeAngelis et al., 2021). In studies on biological invasion, mathematical models have been used efficiently for a few decades aiming to identify different invasion scenarios, to reveal the effect of various factors on invasion success and thus to facilitate understanding of the phenomenon (Hengeveld, 1989; Shigesada and Kawasaki, 1997; Lewis et al., 2016). Economic issues such as losses and associated costs have been a focus of modelling studies too (e.g. see Marten and Moore, 2011), although this line of research, in our opinion, remains under-developed.

The present study, for the first time, presents a conceptual model which monetizes the cost of inaction concerning IAS management. While the cost of inaction is often implicitly assumed to be zero, here we show that it can take on a very high value. We hope that this conceptual demonstration can help motivate the collection of necessary data that allow for more comprehensive empirical estimates of the cost of inaction. We have demonstrated the suitability of this approach for a suite of genera which have both damage and management costs that closely resemble logistic growth through time. Parameterizing these curves alone

513 helps to understand the rate at which the costs of each IAS is accruing, and the estimated total cumulative cost of these IAS in the future. Further, we have confirmed, using our relatively data-rich Aedes spp. case study, that more rapid management interventions and higher management efforts can greatly reduce inaction costs - at the near-billion US\$ scale over two decades for this genus alone. Moreover, our cautionary identification of 'runaway' points

518 should motivate timely management prior to the closing of IAS windows of opportunity for 519 efficient and effective control. We expect our results to help resource managers justify early 520 action, even if initially costly, and accordingly decision makers to fund it, in order to 521 simultaneously increase efficiency, efficacy and decrease overall costs.

\section{Declarations}

\section{Funding}


The authors acknowledge the French National Research Agency (ANR-14-CE02-0021) and the BNP-Paribas Foundation Climate Initiative for funding the InvaCost project that allowed the construction of the InvaCost database. The present work was conducted following a workshop funded by the AXA Research Fund Chair of Invasion Biology and is part of the AlienScenarios project funded by BiodivERsA and Belmont-Forum call 2018 on biodiversity scenarios. DAA is funded by the Kuwait Foundation for the Advancement of Sciences (KFAS), grant no. PR1914SM-01 and the Gulf University for Science and Technology (GUST) internal seed fund, grant no. 187092. RNC acknowledges funding from the Alexander von Humboldt Foundation. EJH is supported by a Fonds de recherche du Québec - nature et téchnologies B3X fellowship.

\section{Conflict of interest}

The authors have declared that no competing interests exist.

\section{Availability of data and material}

The data used in this work come from publicly available databases (sTwist:https://zenodo.org/record/3925164\#.YDv-dS3b0Wo; InvaCost: https://doi.org/10.6084/m9.figshare.12668570). Derived data used for curve parameterization are provided at https://github.com/emmajhudgins/CostOfInaction.

\section{Code availability}

Code and derived data are provided at https://github.com/emmajhudgins/CostOfInaction.

\section{Authors' contributions}

Conceptualization - DAA, EJH, RNC, MK, PJH, BLb, CL, BLn, FC

Dataset (conception, finalisation) - CD, FC

Analyses - DAA, EJH

Methodology - DAA, EJH, BLn, FC

Writing - All authors

Visualizations - DAA, PJH, FC

\section{References}

Abrahams, P., Bateman, M., Beale, T., Clottey, V., Cock, M., et al., 2017. Fall Armyworm: Impacts and implications for Africa, CABI, UK.

Ahmed, D.A., Hudgins, E.J., Cuthbert, R.N., Haubrock, P.J., Renault, D., et al., Modelling the damage costs of invasive alien species. Biological Invasions, in review.

Amarasekare, P. 1998. Allee effects in metapopulation dynamics. American Naturalist, 152, 298-302. 
Anderson, L.G., Dunn, A.M., Rosewarne, P.J., Stebbing, P.D. 2015. Invaders in hot water: a simple decontamination method to prevent the accidental spread of aquatic invasive non-native species. Biological Invasions, 17, 2287-2297.

Angulo, E., Diagne C., Ballesteros-Mejia, L., Akulov, E.N., Dia, C.A.K.M., et al., 2021. Non-English languages enrich scientific data: the example of the costs of biological invasions. Science of the Total Environment, in press.

Barbet-Massin, M., Salles, J-M., Courchamp, F. 2020. The economic cost of control of the invasive yellow-legged Asian hornet. NeoBiota, 55, 11-25.

Bellard, C., Jeschke, J.M. 2016. A spatial mismatch between invader impacts and research publications: Biological Invasions and Geographic Bias. Conservation Biology, 30, 230-232. https://doi.org/10/gg9dph

Bellard, C., Rysman, J-F., Leroy, B., Claud, C. \& Mace, G.M. 2017. A global picture of biological invasion threat on islands, Nature Ecology and Evolution , 1(12), 18621869. doi:10.1038/s41559-017-0365-6.

Blackburn, T.M., Bellard, C., Ricciardi, A. 2019. Alien versus native species as drivers of recent extinctions. Frontiers in Ecology and the Environment, 17, 203-207.

Coughlan, N.E., Cuthbert, R.N., Dick, J.T.A. 2020. Aquatic biosecurity remains a damp squib. Biodiversity and Conservation, 29, 3091-3093.

Courchamp, F., Fournier, A., Bellard, C., Bertelsmeier, C., Bonnaud, et al., 2017. Invasion biology: specific problems and possible solutions. Trends in ecology \& evolution, 32(1), 13-22.

Crooks, J. A. 2005. Lag times and exotic species: The ecology and management of biological invasions in slow-motion1. Ecoscience, 12(3), 316-329.

Crystal-Ornelas, R., Lockwood, J.L. 2020. The 'known unknowns' of invasive species impact measurement. Biological Invasions, 22, 1513-1525.

DeAngelis, D.L., Franco, D., Hastings, A., Hilker, F.M., Lenhart, S., et al., 2021. Towards building a sustainable future: Positioning ecological modelling for impact in ecosystems management. Submitted to Bulletin of Mathematical Biology.

Diagne, C., Leroy, B., Gozlan, R.E., Vaissiere, A.C., Assailly, C., et al., 2020a. InvaCost: a public database of the economic costs of biological invasions worldwide. Scientific Data, 7, 277.

Diagne, C., Catford, J.A., Essl, F., Nuñez, M.A., Courchamp, F. 2020b. What are the economic costs of biological invasions? A complex topic requiring international and interdisciplinary expertise. NeoBiota, in press.

Diagne, C., Leroy, B., Vaissière, A.C., Gozlan, R.E., Roiz, D., et al., 2021. Increasing global economic costs of biological invasions. Nature, in press. 
Essl, F., Dullinger, S., Rabitsch, W., Hulme, P. E., Hülber, K., et al., 2011. Socioeconomic legacy yields an invasion debt. Proceedings of the National Academy of Sciences, 108(1), 203-207.

Finnoff, D., Shogren, J. F., Leung, B. \& Lodge, D. 2007. Take a risk: preferring prevention over control of biological invaders. Ecological Economics 62(2), 216-222.

Francis, T.B., Abbott, K.C., Cuddington, K., Gellner, G., Hastings, A., et al., 2021. Management implications of long transients in ecological systems. Nature Ecology \& Evolution, 5, 285-294.

Haubrock, P.J., Bernery, C., Cuthbert, R.N., Liu, C., Kourantidou, M., et al., What is the recorded economic cost of alien invasive fishes worldwide? Biological Invasions, in review.

Hengeveld, R. 1989. Dynamics of Biological Invasions. Chapman and Hall, London.

Hoffmann, B.D., \& Broadhurst, L.M. 2016. The economic cost of managing invasive species in Australia. NeoBiota 31. 1-18. https://doi.org/10/gg8xkg

Holmes, T. P., Aukema, J. E., Von Holle, B., Liebhold, A., \& Sills, E. 2009. Economic impacts of invasive species in forest past, present, and future. In: The Year In Ecology and Conservation Biology, 2009. Ann. NY Acad. Sci. 1162, 18-38.

IPBES 2019. Summary for policymakers of the global assessment report on biodiversity and ecosystem services of the Intergovernmental Science-Policy Platform on Biodiversity and Ecosystem Services. S. Díaz, J. Settele, E. S. Brondízio E.S., H. T. Ngo, M. Guèze, J. Agard, A. Arneth, P. Balvanera, K. A. Brauman, S. H. M. Butchart, K. M. A. Chan, L. A. Garibaldi, K. Ichii, J. Liu, S. M. Subramanian, G. F. Midgley, P. Miloslavich, Z. Molnár, D. Obura, A. Pfaff, S. Polasky, A. Purvis, J. Razzaque, B. Reyers, R. Roy Chowdhury, Y. J. Shin, I. J. Visseren-Hamakers, K. J. Willis, and C. N. Zayas (eds.). IPBES secretariat, Bonn, Germany. 56 pages. https://doi.org/10.5281/zenodo.3553579

Jones H.P., Holmes N.D., Butchart S.H.M., Tershy B.R., Kappes P.J., et. al. 2016. Invasivemammal eradication on islands results in substantial conservation gains. Proceedings of the National Academy of Sciences. DOI: 10.1073/pnas.1521179113.

Jones, B.A. 2017. Invasive species impacts on human well-being using the life satisfaction index. Ecological Economics, 134, 250-257.

Kumschick, S., Gaertner, M., Vilà, M., Essl, F., Jeschke, J.M., et al., 2015. Ecological impacts of alien species: quantification, scope, caveats, and recommendations. BioScience, 65, 55-63.

Leung, B., Lodge, D.M., Finnoff, D., Shogren, J.F., Lewis, M.A., et al., 2002 An ounce of prevention or a pound of cure: bioeconomic risk analysis of invasive species. Proceedings of the Royal Society B: Biological Sciences, 269, 2407-2413. 
631

632

633

634

635

636

637

638

639

640

641

642

643

644

645

646

647

648

649

650

651

652

653

654

655

656

657

658

659

660

661

662

663

664

665

666

667

Leung, B., Springborn, M. R., Turner, J. A., \& Brockerhoff, E. G. 2014. Pathway-level risk analysis: the net present value of an invasive species policy in the US. Frontiers in Ecology and the Environment, 12(5), 273-279.

Leroy B., Diagne, C., \& Vaissière, A.C. 2020. invacost: INVACOST Database With Methods To Analyse Invasion Costs. R package version 0.2-4.

Lewis, M.A., Petrovskii, S.V., Potts, J. 2016. The Mathematics Behind Biological Invasions. Interdisciplinary Applied Mathematics, Vol. 44. Springer, New York.

Lin, Y., Zhan, A., Hernandez, M. R., Paolucci, E., MacIsaac, H. J., \& Briski, E. 2020. Can chlorination of ballast water reduce biological invasions?. Journal of Applied Ecology, 57(2), 331-343.

Lodge, D.M., Simonin, P.W., Burgiel, S.W., Keller, R.P., Bossenbroek, J.M., et al.,(2016) Risk analysis and bioeconomics of invasive species to inform policy and management. Annual Review of Environment and Resources, 41, 453-488. https://doi.org/10.1146/annurev-environ-110615-085532.

Lougheed, T. 2007. Rooting out invasive species: lessons from down under. Environmental Health Perspectives, 115, A352-A357.

Louppe, V., Leroy, B., Herrel, A., \& Veron, G. 2019. Current and future climatic regions favourable for a globally introduced wild carnivore, the raccoon Procyon lotor. Scientific reports, 9(1), 1-13.

Marten, A., Moore, C.C. 2011. An options based bioeconomic model for biological and chemical control of invasive species. Ecological Economics, 70(11), 2050-2061.

Paini, D.R., Sheppard, A.W., Cook, D.C., De Barro, P.J., Worner, S.P., et al., 2016. Global threat to agriculture from invasive species. Proceedings of the National Academy of Sciences, 113, 7575-7579.

Parker, I. M., Simberloff, D., Lonsdale, W. M., Goodell, K., Wonham, M., et al., 1999. Impact: toward a framework for understanding the ecological effects of invaders. Biological invasions, 1(1), 3-19.

Pejchar, L., Mooney, H.A. 2009. Invasive species, ecosystem services and human well-being. Trends in Ecology and Evolution, 24, 497-504.

Pyšek, P., Hulme, P.E., Simberloff, D., Bacher, S., Blackburn, T.M., et al., 2020. Scientists' warning on invasive alien species. Biological Reviews, 95, 1511-1534.

Ricciardi, A., MacIsaac, H.J. 2011. Impacts of biological invasions on freshwater ecosystems. Fifty years of invasion ecology: the legacy of Charles Elton, 1, 211-224.

Russell, J.C., Innes, J.G., Brown, P.H., \& Byrom, A.E., 2015. Predator-Free New Zealand: Conservation Country. Bioscience, 65, 520-525. doi:10.1093/biosci/biv012

Schaffner, U., Steinbach, S., Sun, Y., Skjøth, C.A., de Weger, L.A., et al., 20Nature Communications 11, 1-7. https://doi.org/10/ghcmx9 
Seebens, H., Blackburn, T.M., Dyer, E.E., Genovesi, P., Hulme, P.E., et al., 2017. No saturation in the accumulation of alien species worldwide. Nature Communications, 8 , 14435.

Seebens, H., Clarke, D. A., Groom, Q., García-Berthou, E., Kühn, I., et al., 2020. A workflow for standardising and integrating alien species distribution data. NeoBiota 59: 39-59.

Shabani, F., Ahmadi, M., Kumar, L., Sohljouy-fard, S., Tehrany, M.S., et al., 2020. Invasive weed species' threats to global biodiversity: Future scenarios of changes in the number of invasive species in a changing climate. Ecological Indicators, 116, 106436.

Shannon, C., Quinn, C.H., Stebbing, P.D., Hassall, C., Dunn, A.M. 2018. The practical application of hot water to reduce the introduction and spread of aquatic invasive alien species. Management of Biological Invasions, 9, 417-423.

Shepard, D.S., Coudeville, L, Halasa, Y.A., Zambrano, B, \& Dayan, G.H., 2011. Economic impact of dengue illness in the Americas. The American journal of tropical medicine and hygiene, 84, 200-207. https://doi.org/10/fg6q4j

Shigesada, N., Kawasaki, K. 1997. Biological Invasions: Theory and Practice. Oxford University Press, Oxford.

Simberloff, D., Marti, J-L, Genovesi, P., Maris, V., Wardle, D.A., et al.,Trends in Ecology \& Evolution, 28, 58-66. https://doi.org/10.1016/j.tree.2012.07.013

Timmins, S.M. \& Braithwaite, H. 2002. Early detection of invasive weeds on islands. In: Turning the Tide: The Eradication of Invasive Species, eds. Veitch, C.R. \& Clout, M.N., pp. 311-318. Gland, Switzerland and Cambridge, UK: IUCN SSC Invasive Species Specialist Group, IUCN.

Victorian Government 2010. Invasive plants and animals policy framework, DPI Victoria, Melbourne.

Vilà, M, Basnou, C, Pyšek, P, Josefsson, M., Genovesi, P., et al., 2010. Frontiers in Ecology and the Environment, 8, 135-144. https://doi.org/10/dk9txk.

Walsh, J.R., Carpenter, S.R., \& Vander Zanden, M.J. 2016. Invasive species triggers a massive loss of ecosystem services through a trophic cascade. Proceedings of the National Academy of Sciences, 113, 4081-4085. 
699 Appendix 1. Example calculation of the cost of inaction for Aedes (mosquitoes).

700 Example What is the total amount of savings (cost of inaction) for Aedes at $t=40$ years, if

701 management were to be introduced at $\tau=0$, instead of being delayed by $\tau=20$ years?

702 The cumulative damage cost from Aedes at $t=40$ years is $C(40)=19169.73$ \$US

703 millions, see Fig. 6a.

704 If we consider a scenario where management is introduced at $\tau=0$ (i.e., at the same time

705 when damage costs begin to cumulate), then at $t=40$, damage costs would have potentially

706 reduced by $M(40)=2433.09$ \$US millions, see Fig. 6 b.

707 Therefore, the total amount of reduced losses is then the difference between these costs, and

708 can be computed from eqn. 7:

$709 \varphi(40,0)=C(40)-M(40)=16736.64$ \$US millions.

710 Now consider another scenario where management is introduced at some delayed time $\tau=$

71120 , in this case the damage cost at $t=40$ would have reduced by $M(20)=1591.07$ SUS

712 millions. The total amount of reduced losses is then: $\varphi(40,20)=C(40)-M(20)=$

71317578.66 \$US millions.

714 As expected, the cumulative cost of damages incurred is greater in the latter scenario where

715 management is delayed.

716 The cost of inaction which is the potential savings one can acquire, is the difference of these

717 losses, where management is applied earlier or delayed:

$718 \Phi=\varphi(40,20)-\varphi(40,0)=M(40)-M(20)=842.02$ \$US millions, see also Fig. $6 c$.

719 Note that this can be directly calculated from eqn. 9.

720 In contrast, the cost of inaction at $t=40$ years (in the case where no action is taken) is

$721 \Phi(40, \tau \rightarrow \infty)=2433.09$, and in the long-term saturates to 2497.71 \$US millions.

722 Note that the parameter values reported in the caption of Fig. 6 are rounded to two decimal

723 places for brevity, whereas the above calculation utilised estimated parameters to a higher

724 degree of accuracy, see Appendix 2. 


\section{Appendix 2.}

Table S1. List of parameters used across equations and their definitions.

\begin{tabular}{|c|c|c|}
\hline Parameter & Description & $\begin{array}{l}\text { Parameter values used for the cost of } \\
\text { inaction calculation for Aedes spp. in Section } \\
4.2 \text { and Appendix 1, to a higher degree of } \\
\text { accuracy }\end{array}$ \\
\hline$K$ & $\begin{array}{l}\text { Cost carrying capacity for cumulative } \\
\text { damage costs (US } \$ \text { millions) }\end{array}$ & 19183.48098446320 \\
\hline$C_{0}$ & Initial damage cost (US\$ millions) & 1450.537256354340 \\
\hline$r$ & $\begin{array}{l}\text { Intrinsic growth rate for cumulative damage } \\
\text { costs (per year) }\end{array}$ & 0.243593284247693 \\
\hline$\gamma$ & $\begin{array}{l}\text { Management effort; lies between } \gamma=0 \text { (no } \\
\text { management effort) and } \gamma=1 \text { (maximum } \\
\text { management effort) inclusive. }\end{array}$ & 0.130201583626750 \\
\hline$K_{M}=\gamma K$ & $\begin{array}{l}\text { Cost carrying capacity for cumulative } \\
\text { management costs (proportional to cost } \\
\text { carrying capacity for cumulative damage } \\
\text { costs, US\$ millions) }\end{array}$ & 2497.719603650754 \\
\hline$M_{0}=\gamma C_{0}$ & $\begin{array}{l}\text { Initial cumulative management cost } \\
\text { (proportional to initial cumulative damage } \\
\text { cost, US\$ millions) }\end{array}$ & 188.8622478869361 \\
\hline$r_{M}$ & $\begin{array}{l}\text { Intrinsic growth rate for cumulative } \\
\text { management costs (per year) }\end{array}$ & 0.153294868601048 \\
\hline$\tau$ & Management delay (year) & $\tau=0$ or 20 \\
\hline
\end{tabular}




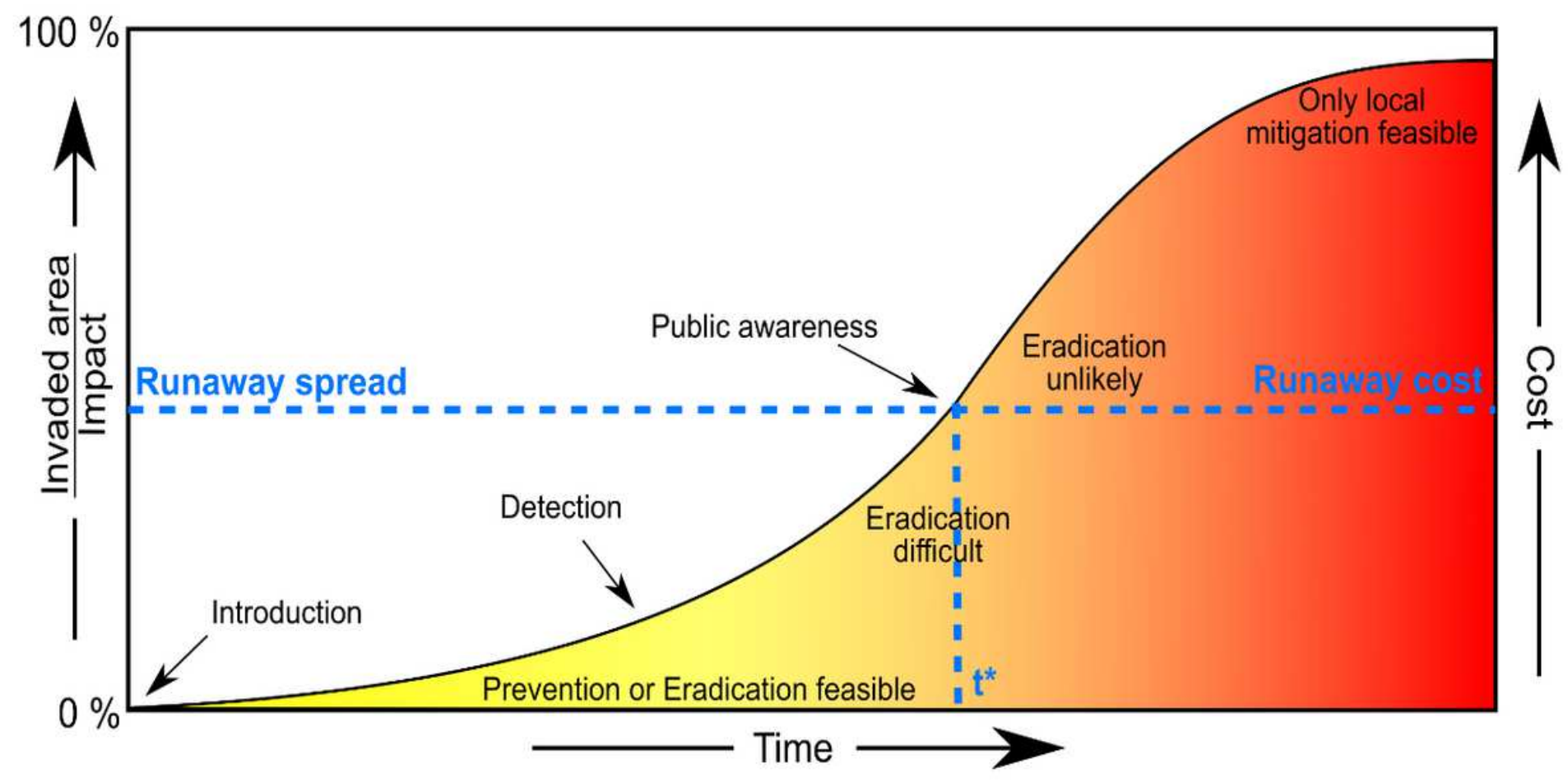

\section{Figure 1}

The classical invasion curve. This relationship displays a generalized invasive alien population response over time, after its introduction and establishment into a new environment. As the population expands and spreads, the area invaded (reported as a percentage of its total invaded area), its impact (damage costs), and its management costs increase following a logistic curve. Management costs, invaded area, and impact all grow at increasing rates until $t^{\wedge \star}$, where they reach their maximum rates (which we call the 'runaway' point, see section 3.5). Adapted from Invasive Plants and Animals Policy Framework, Victorian government, 2010. 

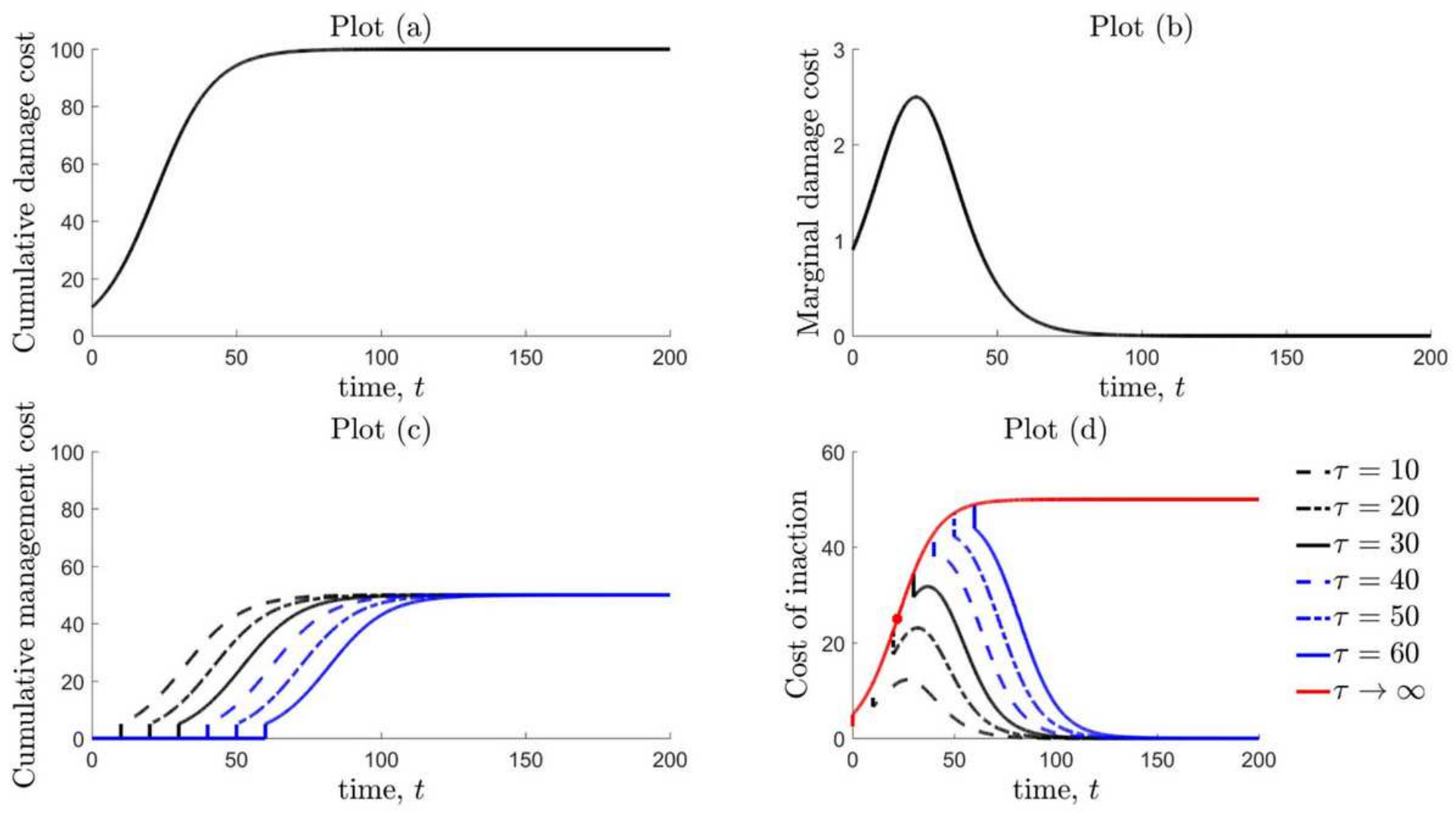

Figure 2

The impact of management delay. Plot (a) shows cumulative damage $\operatorname{costs} \mathrm{C}(\mathrm{t})$, which are modelled using a logistic curve, see eqn. 4. Plot (b) shows the instantaneous damage costs as a function of time (i.e., the marginal cost for each additional year of damage from eqn. 3). Plot (c) shows cumulative management costs $M(t-\tau)$, which are proportional to damage costs according to factor $\gamma$, and delayed by some time $\tau$, see eqn. 5 . Plot $(d)$ shows the cost of inaction $\Phi(t, \tau)$ over time, see eqn. 9 . The red curve illustrates a special case where no action is ever taken, all others represent different scenarios of increasingly delayed management. The red marker is the point of inflection or 'runaway point'. Parameter values in all cases: Damage cost carrying capacity $K=100$, Growth rate $r=r M=0.1$, Initial damage cost $\mathrm{C} 0=10$, Management effort $\gamma=0.5$, Management cost carrying capacity $\mathrm{KM}=\gamma \mathrm{K}=50$, Management delay $\tau$ varied. Figure legend only applies to plots (c) and (d). 

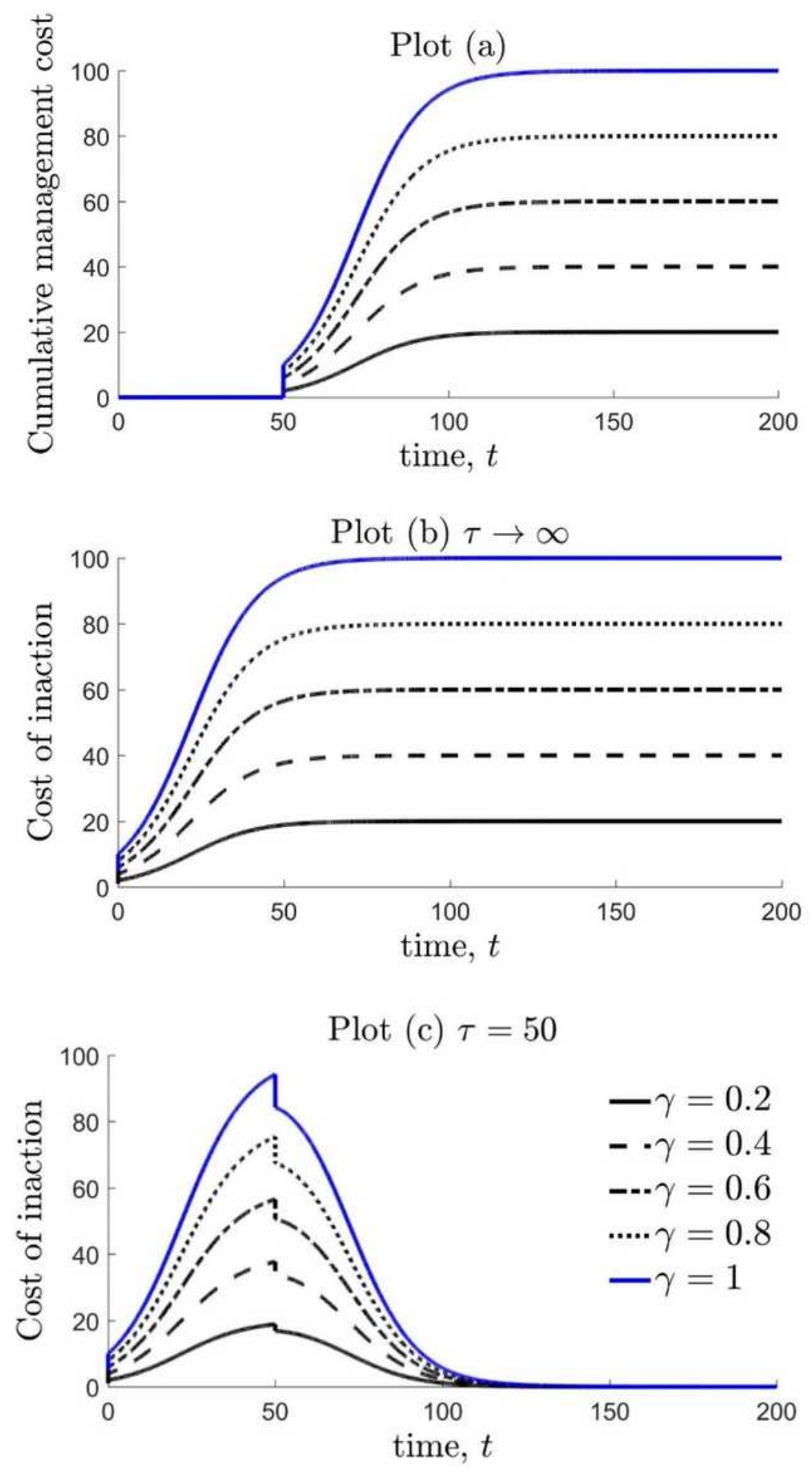

\section{Figure 3}

The impact of management effort. Plot (a) shows management cost curves over time, with a logistic form and a cost carrying capacity $\mathrm{KM}=\mathrm{\gamma K}$, proportional to the damage cost carrying capacity $\mathrm{K}$, with management effort quantified by parameter $\gamma$, see eqn. 5 . They are equivalent to plots of Fig. 2c. Plot (b) shows the associated cost of inaction for an infinite management delay (equivalent to the red curve of Fig. 2d). Plot (c) demonstrates the impact of management effort on the cost of inaction for a delay of 
$\tau=50$. The higher the management costs, the more costly due to delayed management. Parameter values: Cost carrying capacity $K=100$, with management effort $y$ varied. Intrinsic growth rate $r=r M=0.1$, Initial damage cost $\mathrm{C} 0=10$, Management delay $\tau=50$.
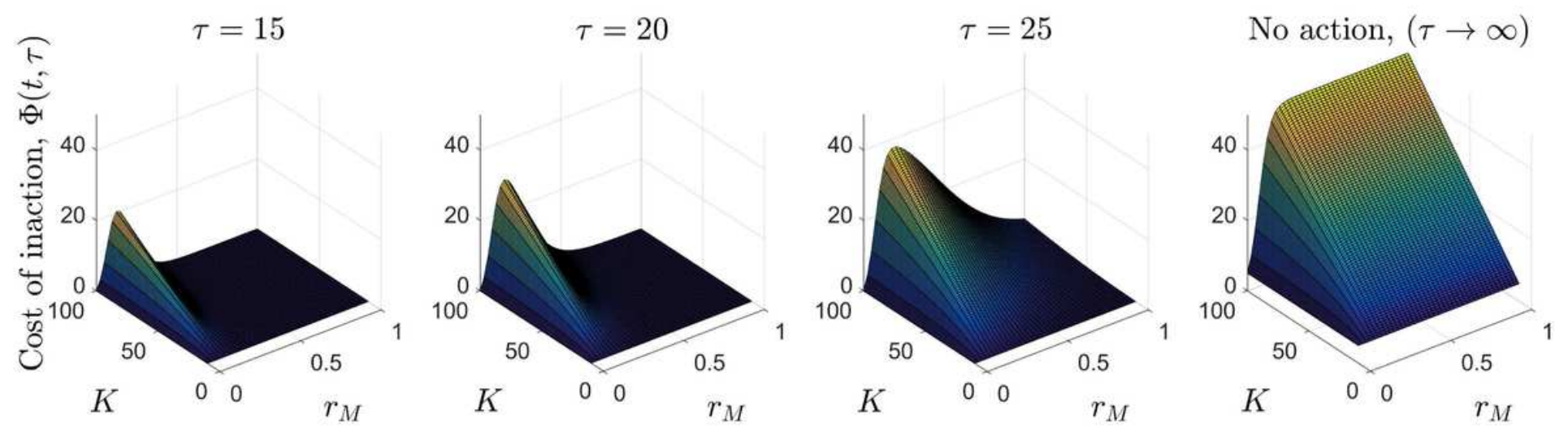

\section{Figure 4}

Snapshots of the cost of inaction at time $t=30$. Management is introduced at different times $\tau$. The limiting case $\tau \mathbb{\infty}$ represents the case where management is not introduced, i.e., no action is taken. Parameter values: Initial damage cost $\mathrm{C} 0=10$, Management effort $\mathrm{Y}=0.5$. 

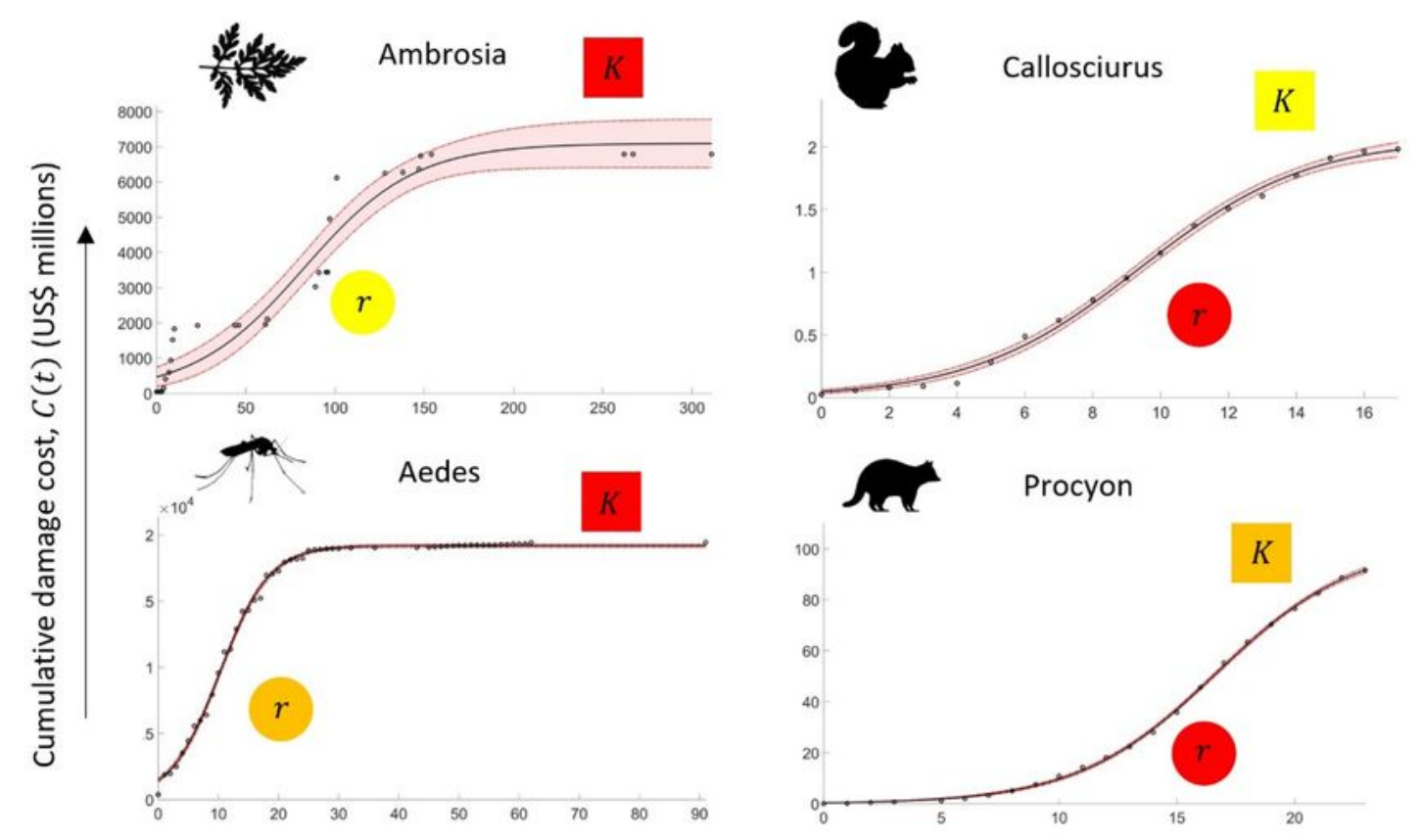

Time since first cost, $t$ (years)

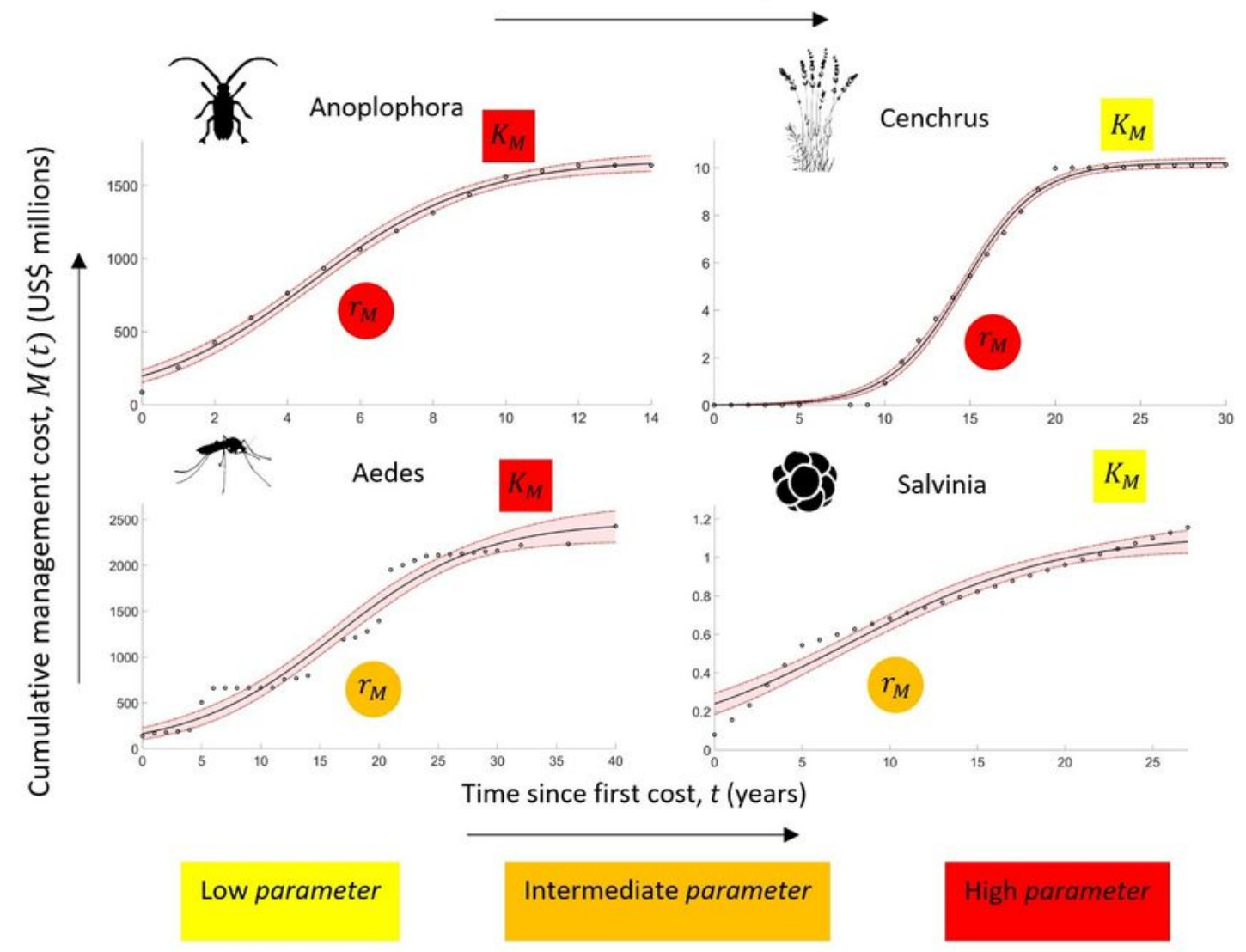

\section{Figure 5}

Model fitting of cumulative damage costs (top) and cumulative management costs (bottom) using a logistic curve, for different invasive alien species. The red shaded areas around the curves represent $95 \%$ confidence regions indicating the range of predicted cumulative costs. The estimated logistic model fit parameters are given in Table 1. The range for low/intermediate/high parameter values are given in the caption of Table 1 using the same colour scheme. High values of the intrinsic growth rate ( $r$ or $\left.r \_M\right)$ 
illustrate species for which costs increase rapidly; high values of the cost carrying capacity ( $\mathrm{K}$ or $\mathbb{K} \mathrm{K} \_\mathrm{M}$ ) illustrate species for which costs eventually saturate at high values. Dots represent annual total costs. Note that the scales differ across subplots.
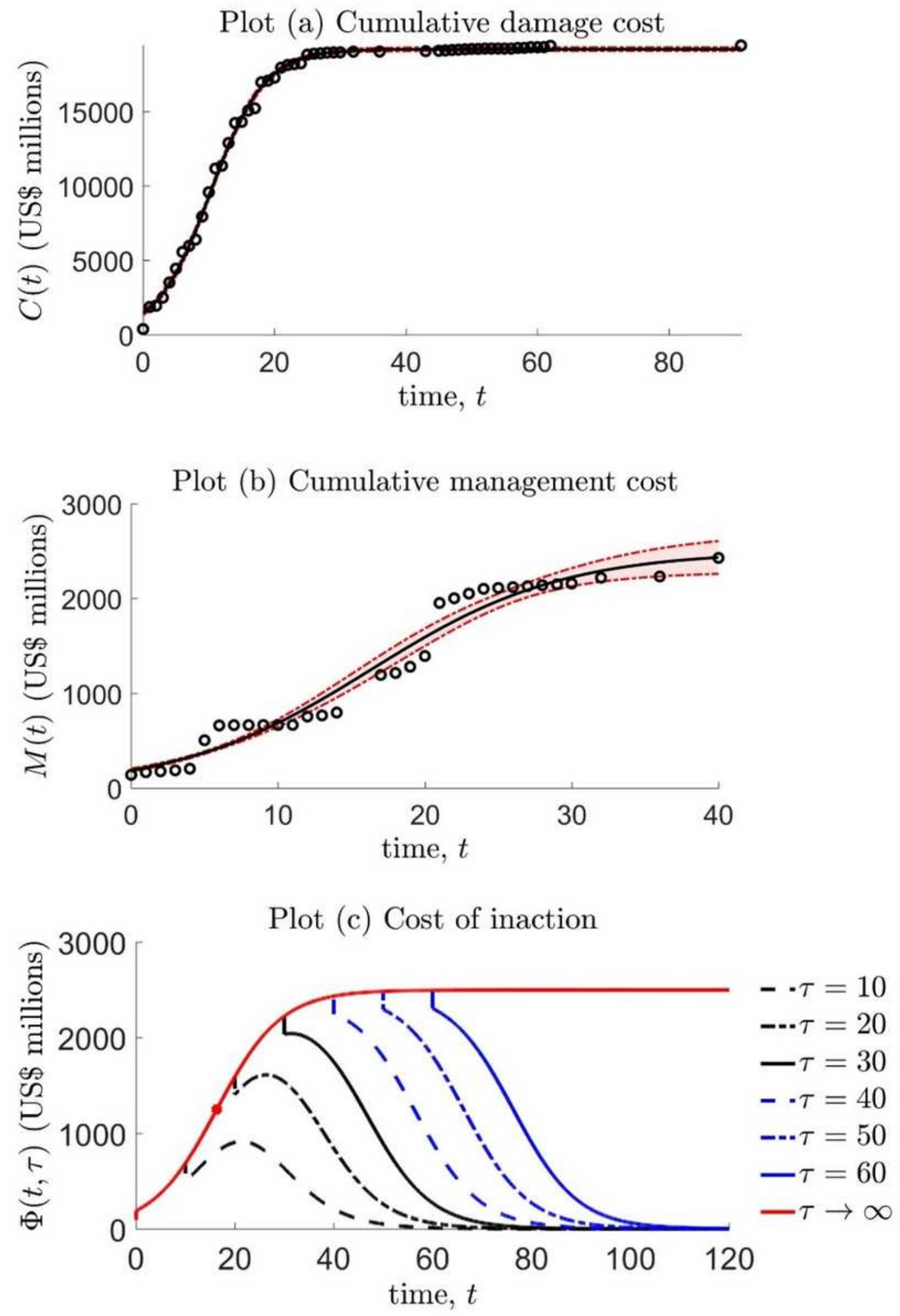

Figure 6

Plot (a) Cumulative damage cost for Aedes. Parameters: Initial damage cost $\mathbb{C} \mathbb{C} \_0=1450.54$, cost carrying capacity $K=19183.48$, intrinsic growth rate $r=0.24$, coefficient of determination $\otimes R \rrbracket^{\wedge} 2=0.997$. Plot 
(b) Cumulative management cost for Aedes. Parameters: Initial management cost $\mathbb{M} \mathbb{M} \_0=\square \gamma \mathrm{C} \square$ $\_0=188.86$, cost carrying capacity $\mathbb{K} \mathbb{K} \otimes \mathrm{M}=\mathrm{\gamma K}=2497.63$, where $\gamma=0.13$ quantifies management effort, intrinsic growth rate $r_{-} M=0.15, R^{\wedge} 2=0.965$. Red shaded area represents a $95 \%$ confidence region. Plot (c) shows the cost of inaction for Aedes, with management delay $\tau$. The red marker is the runaway point which occurs at $\left(t^{\wedge \star}, \Phi^{\wedge \star}\right)=(16.33,1248.86)$. Note that the estimated parameters for management costs differ from those reported in Table 1, as here it is assumed that cost carrying capacities are directly proportional. Also, the parameter values reported here are rounded to two decimal places, but all computations use estimated parameter values to a higher degree of accuracy, see Appendix 2. 